\title{
UAV-Based Remote Sensing Technique to Detect Citrus Canker Disease Utilizing Hyperspectral Imaging and Machine Learning
}

\author{
Jaafar Abdulridha ${ }^{1}$, Ozgur Batuman ${ }^{2}$ and Yiannis Ampatzidis ${ }^{1, * \mathbb{D}}$ \\ 1 Agricultural and Biological Engineering department, Southwest Florida Research and Education Center, \\ University of Florida, IFAS, 2685 SR 29 North Immokalee, FL 34142, USA; ftash@ufl.edu \\ 2 Department of Plant Pathology, Southwest Florida Research and Education Center, University of Florida, \\ IFAS, 2685 SR 29 North Immokalee, FL 34142, USA; obatuman@ufl.edu \\ * Correspondence: i.ampatzidis@ufl.edu; Tel.: +01-239-658-3451
}

Received: 29 April 2019; Accepted: 6 June 2019; Published: 8 June 2019

check for

Abstract: A remote sensing technique was developed to detect citrus canker in laboratory conditions and was verified in the grove by utilizing an unmanned aerial vehicle (UAV). In the laboratory, a hyperspectral (400-1000 nm) imaging system was utilized for the detection of citrus canker in several disease development stages (i.e., asymptomatic, early, and late symptoms) on Sugar Belle leaves and immature (green) fruit by using two classification methods: (i) radial basis function (RBF) and (ii) K nearest neighbor (KNN). The same imaging system mounted on an UAV was used to detect citrus canker on tree canopies in the orchard. The overall classification accuracy of the RBF was higher $(94 \%, 96 \%$, and $100 \%)$ than the KNN method (94\%, 95\%, and $96 \%)$ for detecting canker in leaves. Among the 31 studied vegetation indices, the water index (WI) and the Modified Chlorophyll Absorption in Reflectance Index (ARI and TCARI 1) more accurately detected canker in laboratory and in orchard conditions, respectively. Immature fruit was not a reliable tissue for early detection of canker. However, the proposed technique successfully distinguished the late stage canker-infected fruit with $92 \%$ classification accuracy. The UAV-based technique achieved $100 \%$ classification accuracy for identifying healthy and canker-infected trees.

Keywords: citrus; canker; disease detection; hyperspectral imaging; neural networks; vegetation indices

\section{Introduction}

Citrus bacterial canker (CBC), caused by Xanthomonas citri subsp. citri (Xcc; syn. X. axonopodis pv. citri), is a serious disease of citrus worldwide [1,2]. Symptoms include necrotic, raised lesions with yellow halos on fruit, leaves, and twigs [3]. The bacterium is dispersed by wind and rain and prefers humid-wet climates [1]. On severely infected trees, the pathogen can cause severe premature leaf and fruit drop, twig dieback, blemished fruit, and tree decline, resulting in significant economic impacts [3]. Late symptoms of this disease may appear within only a few months from the infection. Visually, a plant may look healthy, but in fact, the bacterial growth stages take a few months to show symptoms. The disease may spread widely in different ways, including natural events such as storms and hurricanes [4]. Contaminated equipment can also spread this disease [5]. Another common way that this disease is spread is by transportation of diseased or seemingly healthy trees to regions that were previously not infected. CBC is treated with copper applications and is most effective when used on new flush before the infection. It is necessary to apply copper multiple times in order to maintain control of CBC during the most susceptible stages of leaf and fruit growth [6]. The asymptomatic stage of this disease is the critical stage to treat a tree, either by using copper-based 
pesticide and/or bactericide. This, in turn, can prevent the disease from spreading throughout the entire grove. Detection of $X_{C C}$ in plants relies on culturing and polymerase chain reaction (PCR) techniques [7,8]. Although PCR diagnosis can be rapid, there is a risk for false negative results due to the presence of PCR inhibitors in the samples [6]. Culture-based diagnosis is more reliable but can take up to a week to get results and requires samples to be brought into the lab for diagnosis. Thus, an early and accurate disease detection method, before the late symptoms appear, is needed.

Several remote sensing technologies and techniques (e.g., machine vision, hyperspectral imaging) have been developed to scout agricultural fields and detect pests, diseases, and disorders $[9,10]$. These systems generate substantial datasets; the analysis of these datasets require advanced algorithms and high computational power. Machine learning methods provide a powerful tool to analyze such big datasets (e.g., hyperspectral data) for plant disease detection. For example, Ashourloo et al. [11] utilized three machine learning methods (partial least square regression, support vector regression, and Gaussian process regression) to detect wheat leaf rust disease with high classification accuracy. Zhang et al. [12] studied two imaging techniques, hyperspectral and multispectral, to detect and distinguish apples with wind damage, insect damage, bruises, decay, hail, russeting, spot, scar, stem, and calyx. The hyperspectral imaging technique achieved $93.6 \%$ accuracy and the multispectral imaging obtained 91.4\% overall accuracy. Behmann et al. [13] measured the hyperspectral reflectance of table grapes (seven cultivars) to predict some physico-chemical ( $\mathrm{pH}$, total acidity, and solid soluble content) and sensory indices. They obtained high correlation (80-94\%) between hyperspectral reflectance values and physicochemical indices. Abdulridha et al. [14] detected laurel wilt disease with a six band multispectral camera in order to differentiate it from other biotic and abiotic stress factors such as $\mathrm{N}$ and Fe efficiency, and phytophthora root rot disease. The classification results reached up to $100 \%$ in some cases. Lu et al. [15] also detected anthracnose crown rot in strawberries utilizing spectroradiometric technology in asymptomatic and late development stage utilizing three classification discriminant analysis algorithms (fisher discriminant analysis, FDA; stepwise discriminant analysis, SDA; and K-nearest neighbor algorithm, KNN). The classification results were $71.3 \%, 70.5 \%$, and $73.6 \%$ for SDA, FDA, and KNN, respectively.

Unmanned aerial vehicles (UAVs) have recently been utilized in precision agriculture for weed and disease detection, vegetation coverage detection and assessment, and nutrient status and growth vigor assessment [16,17]. Zhang et al. [18] monitored the growth of turf grass in different trails by using a UAV and several vegetation indices (e.g., Normalized Difference Vegetation Index (NDVI), Visible Atmospherically Resistant Index VARI). Albetis et al. [19] developed a UAV-based multispectral technique to distinguish between two diseases with similar symptoms, Flavescence dorée and grapevine trunk disease, in vineyards. The infected (based on this detection technique) plants were removed after detection [20]. Several studies in remote sensing recommended the use of UAVs for precision agricultural applications [16,21-23].

In citrus, Qin et al. [24] developed a method to detect citrus canker, greasy spots, insect damage, melanose, scab, and wind scar on grapefruits by analyzing wavelengths between $450 \mathrm{~nm}$ and $930 \mathrm{~nm}$ through hyperspectral imaging with a classification accuracy of $95 \%$ under indoor conditions. Similarly, Weng et al. [25] successfully utilized a hyperspectral technology to determine Huanglongbing (HLB) in the asymptomatic and symptomatic development stages. By comparing the reflectance of these stages with other nutrient deficiency symptoms, they were able to distinguish the diseased (early and late stages) from non-diseased plants. Furthermore, they combined hyperspectral imaging with carbohydrate metabolic analysis for HLB detection in different seasons and cultivars. The results were more than $94 \%$ accurate in all tested periods and seasons. Sharif et al. [26] analyzed several citrus diseases and infections using imaging techniques to distinguish between anthracnose, black spot, canker, scab, greening (HLB), and melanose symptoms. They were able to detect various types of lesion on the citrus fruits and leaves. The classification accuracy, using a multiclass support vector machine (SVM), was 94\%. Zhang et al. [27] achieved promising results utilizing non-destructive methods and several classification techniques to detect citrus diseases and disorders on fruits. Using tree-type SVM 
models, the classification accuracies of healthy, HLB, melanose, oil spot, wind scar, leaf miner, and rust mite were $98.4 \%, 90.8 \%, 95.2 \%, 92.0 \%, 90.8 \%, 95.2 \%$, and $96.8 \%$, respectively. The proposed appropriate waveband selection methods were, therefore, very effective in extracting features of citrus fruit with these blemishes. Sankaran et al. [28] used a portable spectrometer (visible-near-infrared) to detect HLB disease in citrus trees; reflectance data was analyzed as first and second derivatives, and the overall classification accuracy of the detection system was more than 90\%. Similarly, Mishra et al. [29] utilized visible-near infrared spectroscopy and three classification methods (k-nearest neighbor, logistic regression, and support vector machines) to detect HLB in tree canopies with more than $90 \%$ accuracy. Sankaran and Ehsani [30] developed a technique to distinguish healthy citrus leaves from leaves affected with canker and HLB by using portable spectroscopy (visible-near infrared and mid-infrared) and two classifiers (quadratic discriminant analysis and k-nearest neighbor). They achieved more than $90 \%$ classification accuracy.

Nevertheless, previous studies have all been focused on detecting canker disease on mature (orange color) citrus fruit (grapefruit and orange) and mainly in laboratory conditions [24,31]. The objectives of this study were to (i) detect canker disease on tangerine citrus Sugar Belle leaves and immature (green) fruits in asymptomatic, early, and late disease development stages in laboratory conditions and later in the orchard (outdoors) by utilizing an UAV-based hyperspectral imaging technique; and (ii) classify and select the optimal vegetation indices to detect canker in the above disease stages in both indoor (laboratory) and outdoor (UAV-based technique) environments. To the best of our knowledge, we are the first to develop a UAV-based technique to detect citrus canker in the grove and to identify citrus canker on leaves (indoors and outdoors) and on immature (green) fruits.

\section{Materials and Methods}

\subsection{Experimental Site and Sample Collection}

Tangerine Sugar Belle leaves and immature (green) fruits infected with canker disease and healthy leaves and fruits were collected from an experimental orchard at the University of Florida's Southwest Florida Research and Education Center (SWFREC), Immokalee, Florida, USA, for laboratory assessment on October 2018. Four trees were selected, and 10 leaves were collected from each tree in different disease severity stages including (i) asymptomatic stage (leaves without visible symptom); (ii) early stage (symptoms appear as slightly raised, small, blister-like chlorotic lesions); and (iii) late stage (lesions turn tan and then brown, and the edges appear water-soaked and develop a yellow halo) (Table 1 and Figure $1 \mathrm{a}-\mathrm{d}$ ). Immature (green) fruits were collected from the same orchard in the asymptomatic stage (Figure 1f) and the late stage (Figure 1g). The UAV data was collected in the same field (October 2018, between 10 a.m. to 2 p.m. to minimize variations of light intensity during experiments).

Table 1. Number of leaves collected for each category studied in this work.

\begin{tabular}{ccc}
\hline Category & Number of Leaves & The Symptoms of Leaves \\
\hline Healthy leaves (from the greenhouse) & 40 & No symptoms \\
Asymptomatic stage of canker disease & 40 & No symptoms with a yellow halo. \\
Early stage of canker disease & 40 & Tiny lesion \\
Late stage of canker disease & 40 & Large dark and brown lesion \\
\hline
\end{tabular}




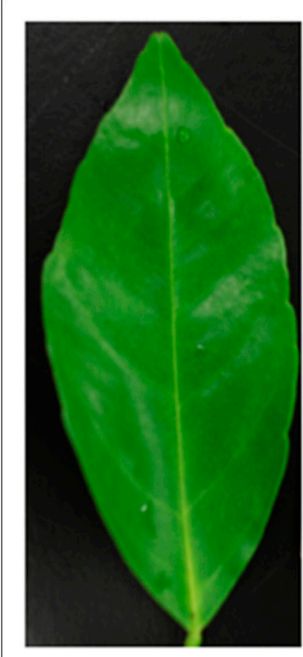

(a)

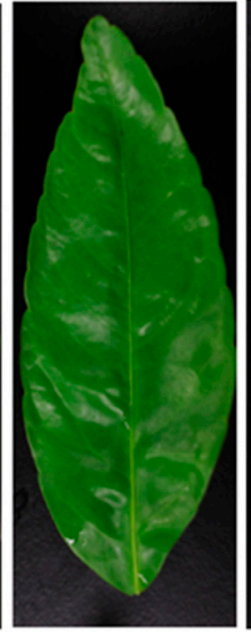

(b)

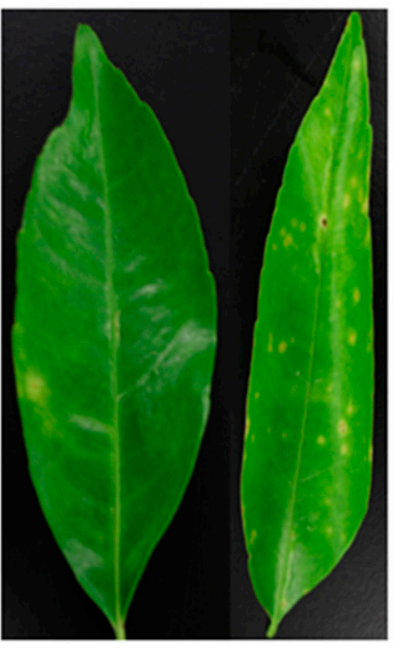

(c)

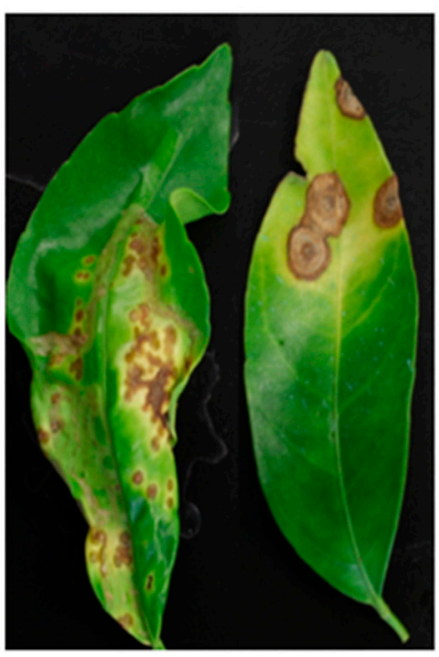

(d)

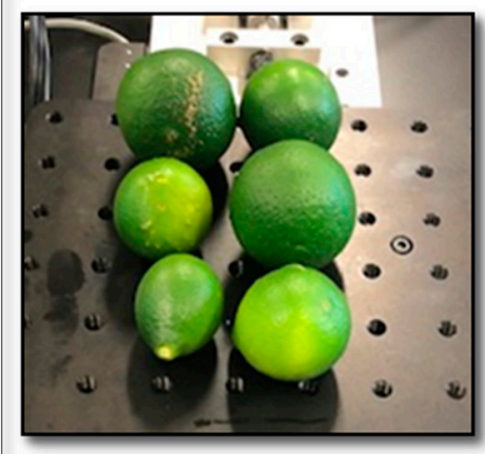

(e)

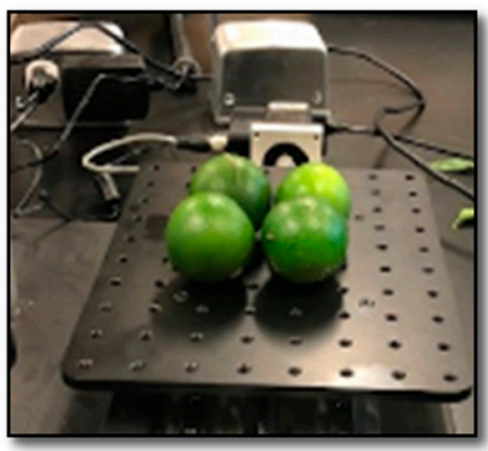

(f)

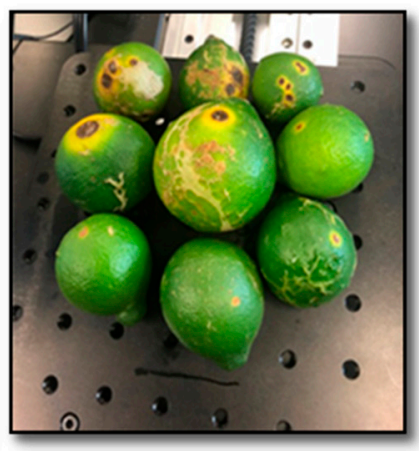

(g)

Figure 1. Example of Sugar Belle leaves (upper panel) representing four categories: (a) healthy; (b) asymptomatic; (c) early, and (d) leaves with late canker developmental stages. Lower panel is examples of Sugar Belle immature (green) fruits representing three categories: (e) non-infected; (f) asymptomatic, and $(\mathrm{g})$ fruits with late canker developmental stages.

\subsection{Bacterium Isolation}

A plant pathologist carefully collected the leaves and fruits from citrus plants in grove, and to confirm Xanthomonas axonopodis bacterial infection, a polymerase chain reaction (PCR) analysis was conducted on the selected leaves and fruits. Healthy leaves and fruits were obtained from potted plants grown in greenhouse conditions.

Tissue was excised from leaf and fruit samples with or without CBC lesions (Figure 1). Early and late $\mathrm{CBC}$ lesions were compared to asymptomatic tissue. Healthy leaves and fruits from citrus plants grown in greenhouse conditions were used as negative control. The citrus tissue was then macerated in $100 \mu \mathrm{L}$ of nuclease-free water to release bacterial cells from tissue. This homogenate was used in PCR assays.

\subsection{Polymerase Chain Reaction (PCR) Analysis}

XACF/XACR primer pairs [7] were used to test for XCc, and primer pairs 27F/1492R [32] were used as a control to test for bacteria. All amplifications were carried out in a final volume of $25 \mu \mathrm{L}$ containing 12.5 $\mu \mathrm{L}$ of DreamTaq Green PCR Master Mix (ThermoFisher, Waltham, MA), $1 \mu \mathrm{L}$ of each primer (Table 1), $9.5 \mu \mathrm{L}$ of nuclease free water, and $1 \mu \mathrm{L}$ of the macerated tissue/water mix. Reactions were run for an initial denaturation step of $5 \mathrm{~min}$ at $95^{\circ} \mathrm{C}$ followed by 35 cycles of $15 \mathrm{~s}$ at $95^{\circ} \mathrm{C}, 30 \mathrm{~s}$ at 
$60{ }^{\circ} \mathrm{C}$, and $30 \mathrm{~s}$ at $72{ }^{\circ} \mathrm{C}$, and final extension of $7 \mathrm{~min}$ at $72{ }^{\circ} \mathrm{C}$. Eight microliters of the PCR reaction was separated out on 1.0\% agarose gel, stained with Apex Safe DNA Gel Stain (Genesee Scientific, San Diego, CA), and visualized on a UV gel imager. Samples with a 561 bp-band was considered a CBC positive sample. Selected CBC-positive bands were excised from the gel and sequenced at MC Lab (San Francisco, CA) for confirmation.

\subsection{Indoor Hyperspectral Data Collection}

Hyperspectral data was collected by a benchtop imaging system comprised of a Pika L 2.4 camera, a mounting tower, lights, a scanning stage, a power supply, and a SpectrononPro control software (Spectronon Pro, Resonon, Bozeman, MT) (Figure 2). The same hyperspectral camera was used indoors and outdoors after replacing lenses to cover a 400-1000 nm spectral range. Resonon's hyperspectral imagers (RHI) are line-scan imagers (also referred to as push-broom imagers). Two-dimensional images are created by gathering the image line by line while the sample is interpreting relative to the camera. This is typically accomplished by placing the sample on a linear translation stage. Focus and calibration sheets were used to set the stage speed and imager frame rate. White panels and dark lines with black covers were utilized for the calibration. The white panel used in laboratory conditions was made of polyethylene plastic (type 822; Spectronon Pro, Resonon, Bozeman, MT). The regions of interest (RoIs) were chosen manually by randomly selecting six spectral scans from each leaf and fruit to avoid any bias (Figure 3).

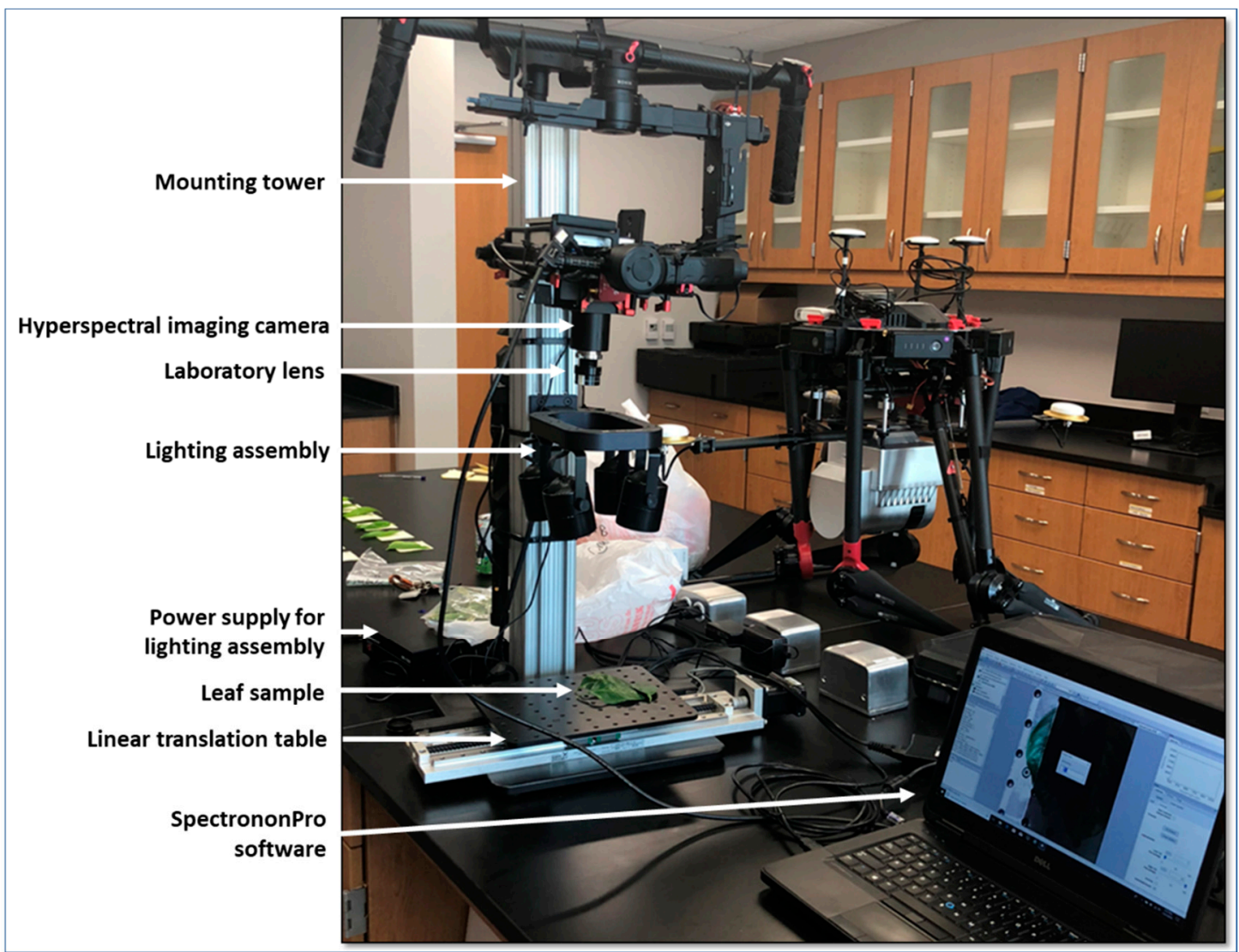

Figure 2. Hyperspectral Resonon Pika L imaging system that was used for indoor data collection with all components shown including tower, lights, stage, software, and a leaf sample. 


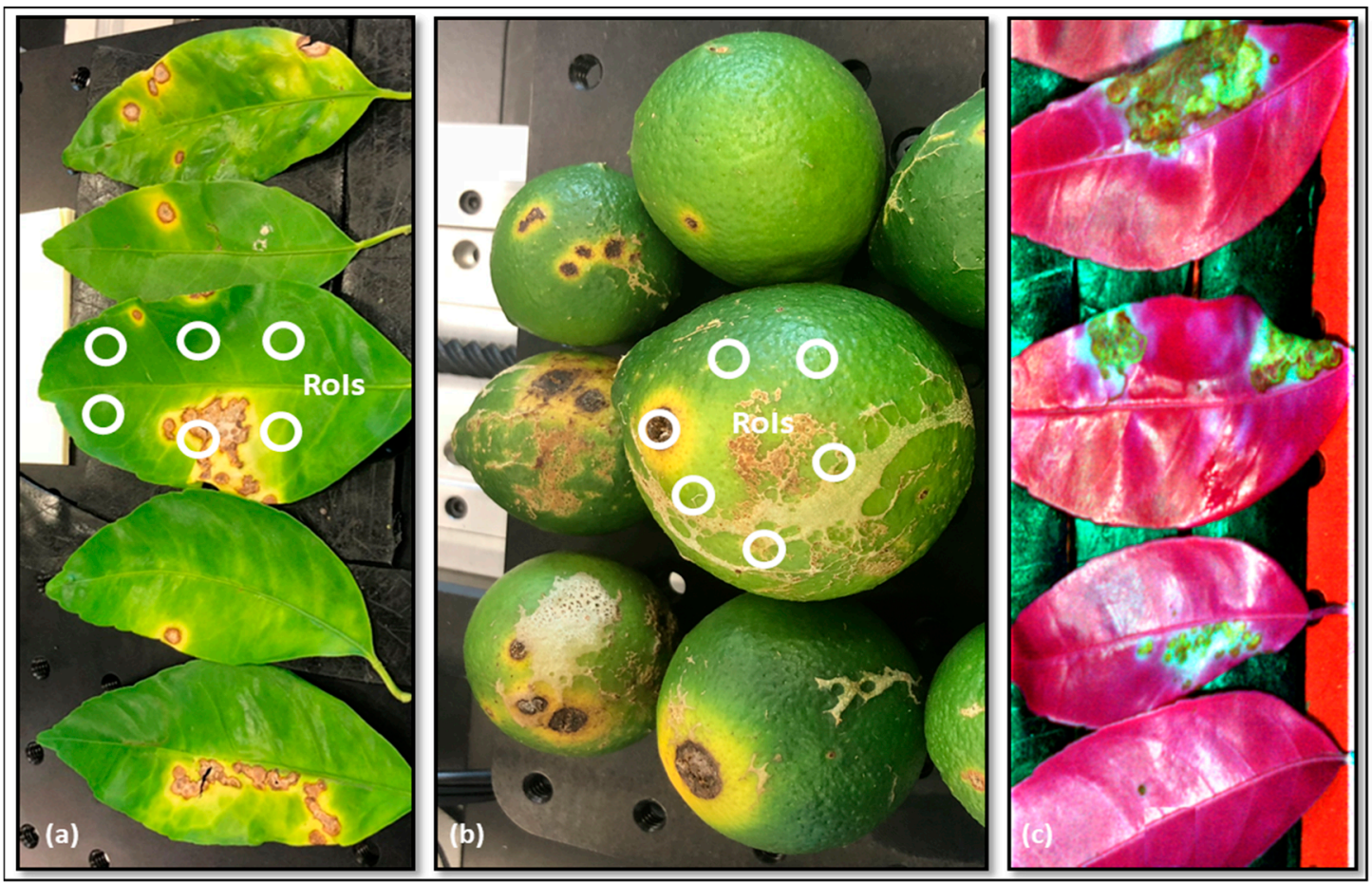

Figure 3. The indoor data collection system that was used for regions of interest (RoI) collection from citrus canker-infected Sugar Belle tangerine tissue samples. (a) Selection of RoIs on leaves and (b) immature fruits are indicated with white circles. Each sample (leaf or fruit) generates six spectral signatures by six randomly selected RoIs. (c) Leaf images showing canker symptoms on leaves with a false color of leaves with lesions in an infrared, blue (450-485 nm), green (500-565 nm), and red $(625-740 \mathrm{~nm})$ wavelengths.

\subsection{Outdoor Hyperspectral Data Collection}

Hyperspectral data was collected by using a UAV (DJI Matrice 600, Pro Hexacopter) and the same hyperspectral camera, Resonon Pika L 2.4 (Figure 4a), as in the indoor procedure. The UAV-based imaging system includes (i) a Resonon Pika L 2.4 hyperspectral camera (Spectronon Pro, Resonon, Bozeman, MT); (ii) visible-near infrared (V-NIR) objective lenses for the Pika L camera with a focal length of $23 \mathrm{~mm}$, field of view (FOV) of 13.1 degrees, and instantaneous field of view (IFOV) of $0.52 \mathrm{mrad}$; and (iii) a global positioning system (GPS) and the inertial measurement unit IMU (DJI) flight control system for multi-rotor aircraft, to record sensor position and orientation. Data was collected at $30 \mathrm{~m}$ above the ground with a speed of $1.5 \mathrm{~m} / \mathrm{h}$. The region of interest was chosen randomly from the developed 2D maps, and the files were saved in KML format. The positions of the infected trees were known (leaves were collected and identified by PCR).

The maps and images were analyzed by the Spectronon software after hyperspectral data were acquired. Calibration corrections were performed using Resonon hyperspectral data analysis software (Spectronon Pro, Resonon, Bozeman, MT). Georectification and radiometric correction plugins, from the Spectronon Pro software, were used to correct the GPS/IMU and the radiometric data, respectively. The regions of interest were selected manually (and randomly) for each tree, and 20 spectral scans were performed to ensure that the entire canopy was covered spectrally (Figure 4). The regions of interest were then exported as a text file and processed using SPSS software (SPSS 13.0, Inc., Chicago; Microsoft Corp., Redmond, WA). Pixel-based reflectance data was mixed for each class. 


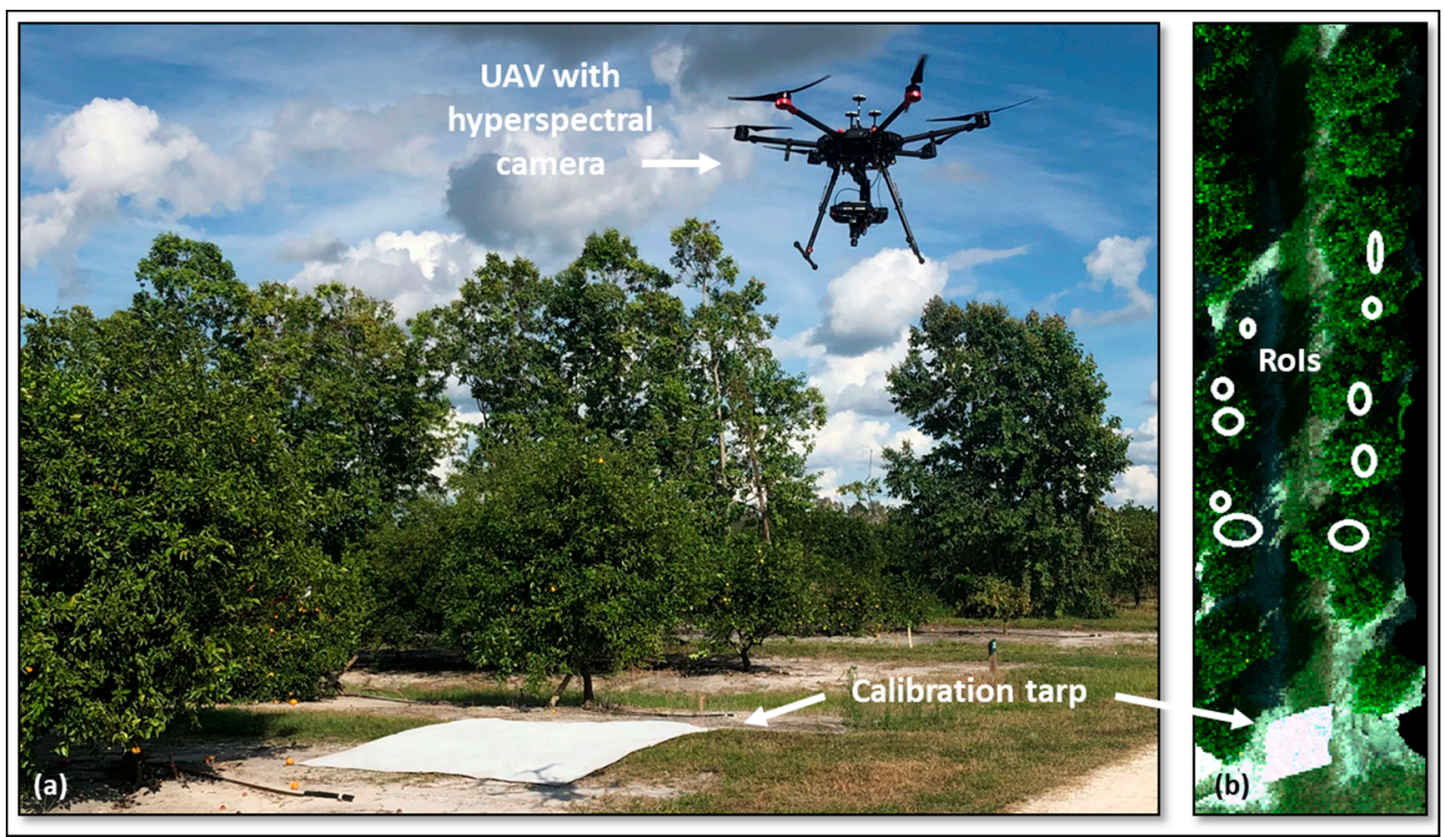

Figure 4. The unmanned aerial vehicle (UAV)-based data collection system that was used for regions of interest (RoI) collection from citrus canker-infected Sugar Belle tangerine trees in the orchard. (a) UAV-based data collection system; (b) random selection of twenty RoIs from citrus trees infected with citrus canker.

\subsection{Data Analysis}

Data obtained from the Resonon imaging system can be categorized into three types as described below.

\subsubsection{Raw data}

After capturing the images, the raw data was preprocessed to eliminate the noise of the instrument, illumination, and model reflectivity. For this, the raw data was calibrated by an imager calibration pack (ICP) with the Radiance Conversion plugin in Spectronon software.

\subsubsection{Reflectance}

During airborne (i.e., UAV) data collection, a gray panel, made from highly durable woven polyester fabric (type 822; Spectronon Pro, Resonon, Bozeman, MT) (Figure 4a-b), was utilized to calibrate the collected data. The reflection values are only accurate when the solar illumination (clouds, sun angle, etc.) does not change during the data collection. To achieve this consistency, we only collected data in a 10 a.m. to 2 p.m. window of the day during our experiments. Data were converted from radiance to reflectance using the Spectronon Reflectance Conversion from the Spectrally Flat Reference Cube plugin software.

\subsubsection{Data analysis procedure}

The Resonon Pika L imaging system was utilized in both outdoor (airborne) and indoor (benchtop) systems. In the benchtop system, images were analyzed using the Spectronon Pro software. Figure 3 presents an example of the selection of RoIs for leaves (Figure 3a) and fruit (Figure 3b). This procedure generates six spectral signatures for each leaf and fruit. Figure $3 \mathrm{c}$ shows the false color of leaves with lesions in an infrared, blue (450-485 nm), green (500-565 nm), and red (625-740 nm) leaf image. Figure 4 presents an example of the RoIs for the UAV-based system (Figure $4 \mathrm{~b}$ ) and their spectral signatures. 


\subsection{Vegetation Indices}

Based on literature review, the most common factors that can be estimated using the visible and near-infrared channels are chlorophyll content, water stress, and cell structure $[33,34]$. In this study, 31 vegetation indices (Vis) were utilized and evaluated to detect citrus canker (Table 2). These indices were chosen to identify citrus canker disease based on chlorophyll reduction and leaf cell damage caused by bacteria. The spectral reflectance was collected in different stages of disease symptom development (asymptomatic, early, and late stage), and healthy leaves were used as a control. VIs measurements will vary from one stage to another based on severity of the disease (i.e., size and number of lesion).

Table 2. List of vegetation indices (VIs) utilized to detect citrus canker in this study

\begin{tabular}{|c|c|c|}
\hline Vegetation Indexes & Equation & References \\
\hline Water Index (WI) & $\mathrm{WI}=\frac{\mathrm{R} 900}{\mathrm{R} 970}$ & Penuelas et al. [33] \\
\hline $\begin{array}{l}\text { Modified Chlorophyll Absorption in } \\
\text { Reflectance Index (mCARI 1) }\end{array}$ & mCARI $1=1.2\left[\left(2.5^{*} \mathrm{R} 761-\mathrm{R} 651\right)-1.3(\mathrm{R} 761-\mathrm{R} 581)\right]$ & Haboudane et al. [34] \\
\hline $\begin{array}{l}\text { Modified Triangular Vegetation Index } 1 \\
\text { (MTVI 1) }\end{array}$ & MTVI $1=1.2[1.2(1.2(R 761-R 581)-2.5(R 651-R 581)]$ & Haboudane et al. [34] \\
\hline $\begin{array}{l}\text { Modified Triangular Vegetation Index } 2 \\
\text { (MTVI 2) }\end{array}$ & $\begin{array}{c}\text { MTVI } 2= \\
\frac{1.5[1.2(\mathrm{R} 761-\mathrm{R} 581)-2.5(\mathrm{R} 651-\mathrm{R} 581)]}{\mathrm{SQ}[(2 * \mathrm{R} 761+1) 2-(6 * \mathrm{R} 761-5 * \mathrm{SQ}(\mathrm{R} 651)-0.5]}\end{array}$ & Haboudane et al. [34] \\
\hline Simple Ratio Index (SR 900) & SR $900=\frac{\mathrm{R} 900}{\mathrm{R} 651}$ & Jordan [35] \\
\hline Simple Ratio Index (SR 850) & $\mathrm{SR} 850=\frac{\mathrm{R} 850}{\mathrm{R} 651}$ & Jordan [35] \\
\hline Green NDVI (GNDVI) & $\mathrm{GNDVI}=\frac{(\mathrm{NIR} 850-\mathrm{G} 580)}{(\mathrm{NIR} 850+\mathrm{G} 580)}$ & Gitelson and Merzlyak [36] \\
\hline Photochemical Reflectance Index (PRI) & $\mathrm{PRI}=\frac{(\mathrm{R} 531-\mathrm{R} 570)}{(\mathrm{R} 531+\mathrm{R} 570)}$ & Gamon et al. [37] \\
\hline $\begin{array}{l}\text { Ratio Analysis of reflectance Spectral } \\
\text { Chlorophyll a (RARSa) }\end{array}$ & $\mathrm{RARSa}=\frac{\mathrm{R} 675}{\mathrm{R} 700}$ & Chappelle et al. [38] \\
\hline $\begin{array}{l}\text { Ratio Analysis of reflectance Spectral } \\
\text { Chlorophyll b (RARSb) }\end{array}$ & $\mathrm{RARSb}=\frac{\mathrm{R} 675}{(\mathrm{R} 700 \times \mathrm{R} 650)}$ & Chappelle et al. [38] \\
\hline Ratio analysis of reflectance spectra (RARSc) & RARSc $=\frac{R 760}{R 500}$ & Chappelle et al. [38] \\
\hline Pigment specific simple ratio (PSSRa) & $\mathrm{PSSRa}=\frac{\mathrm{R} 800}{\mathrm{R} 680}$ & Blackburn [39] \\
\hline $\begin{array}{l}\text { Normalized difference vegetation index } 780 \\
\text { (NDVI 780) }\end{array}$ & NDVI $780=\frac{R 780-R 670}{R 780+R 670}$ & Raun et al. [40] \\
\hline Structure Insensitive Pigment Index (SIPI) & $\mathrm{SIPI}=\frac{(\mathrm{R} 840-\mathrm{R} 450)}{(\mathrm{R} 840-\mathrm{R} 670)}$ & Penuelas et al. [41] \\
\hline $\begin{array}{l}\text { Normalized chlorophyll pigment ratio index } \\
\text { (NCPI) }\end{array}$ & $\mathrm{NCPI}=\frac{(\mathrm{R} 670-\mathrm{R} 450)}{(\mathrm{R} 670-\mathrm{R} 450)}$ & Penuelas et al. [42] \\
\hline $\begin{array}{l}\text { Normalized phaeophytinization index } \\
\text { (NPQI) }\end{array}$ & $\mathrm{NPQI}=\frac{(\mathrm{R} 415-\mathrm{R} 435)}{(\mathrm{R} 415-\mathrm{R} 435)}$ & Barnes et al. [43] \\
\hline Plant Senescence Reflectance Index (PSRI) & PSRI $=\frac{(\mathrm{R} 660-\mathrm{R} 510)}{(\mathrm{R} 760)}$ & Penuelas et al. [44] \\
\hline The ratio of $\mathrm{WI}$ and $\mathrm{ND}(\mathrm{WI} / \mathrm{ND})$ & $\mathrm{WI} / \mathrm{ND}=\frac{\mathrm{R} 750}{\mathrm{R} 600}$ & Hunt et al. [45] \\
\hline $\begin{array}{l}\text { Transform chlorophyll absorption in } \\
\text { reflectance index (TCARI) }\end{array}$ & $\begin{aligned} \text { TCARI }= & 3[(R 740-R 651)-0.2(R 740- \\
& R 581)(R 740 / R 651)]\end{aligned}$ & Haboudane et al. [46] \\
\hline Green Vegetation (VIGreen) & VIGreen $=\frac{(\mathrm{R} 760-\mathrm{R} 651)}{(\mathrm{R} 760+\mathrm{R} 651)}$ & Gitelson et al. [47] \\
\hline Red-Edge Vegetation Stress Index 1 (RVS 1) & RVS $1=\left[\frac{(\text { R651+Red Edge } 750)}{2}\right]-$ Red Edge 733 & Merton [48] \\
\hline Red-Edge Vegetation Stress Index 2 (RVS 2) & RVS $2=\left|\frac{(\text { R651+Red Edge } 750)}{2}\right|-$ Red Edge 751 & Merton [48] \\
\hline Triangle Vegetation Index (TVI) & TVI $=0.5\left[120^{*}(R 761-R 581)-200(R 651-R 581)\right]$ & Broge [49] \\
\hline $\begin{array}{l}\text { Renormalized Difference Vegetation Index } \\
\text { (RDVI) }\end{array}$ & $\mathrm{RDVI}=\frac{(\mathrm{R} 761-\mathrm{R} 651)}{\mathrm{SQ}(\mathrm{R} 761+\mathrm{R} 651)}$ & Roujean et al. [50] \\
\hline $\begin{array}{l}\text { Normalized difference vegetation index } 850 \\
\text { (NDVI 850) }\end{array}$ & NDVI $850=\frac{(\mathrm{R} 850-\mathrm{R} 651)}{(\mathrm{R} 850+\mathrm{R} 651)}$ & Raun et al. [40] \\
\hline Simple Ratio Index (SR 761) & $\mathrm{SR} 761=\frac{\mathrm{R} 761}{\mathrm{R} 651}$ & Jordan [35] \\
\hline $\begin{array}{l}\text { Normalized difference vegetation index } 761 \\
\text { (NDV 761) }\end{array}$ & NDVI $761=\frac{(R 761-R 651)}{(R 761+R 651)}$ & Raun [40] \\
\hline Plant Pigment ratio (PPR) & $\mathrm{PPR}=\frac{(\mathrm{R} 550-\mathrm{R} 450)}{(\mathrm{R} 550+\mathrm{R} 450)}$ & Metternicht [51] \\
\hline $\begin{array}{l}\text { Water Stress and Canopy Temperature } \\
\text { (NWI 2) }\end{array}$ & NWI $2=\frac{R 970-R 850}{R 970+R 850}$ & Babar et al. [52] \\
\hline Nitrogen Reflectance Index (NRI) & $\mathrm{NRI}=\frac{(\mathrm{R} 570-\mathrm{R} 670)}{(\mathrm{R} 570+\mathrm{R} 670)}$ & Bausch and Duke [53] \\
\hline Anthocyanin Reflectance Index (ARI) & $\mathrm{ARI}=\left(\frac{1}{\mathrm{R} 550}\right)-\left(\frac{1}{\mathrm{R} 700}\right)$ & Gitelson [54] \\
\hline
\end{tabular}

\subsection{Spectral Data Classification Methods}

For the classification analysis, SPSS software was utilized to analyze and classify the spectral data of the four categories of leaves: (i) healthy, (ii) asymptomatic, (iii) early, and (iv) late disease development stages. The classification of immature fruit was conducted between three categories: 
(a) healthy, (b) asymptomatic, and (c) late disease development stages. Two classification methods were utilized to analyze the collected data and classify the above categories: (I) the neural network Radial Basis Function (RBF); and (II) the K-nearest neighbor (KNN). These methods were chosen because of their high classification accuracy in similar studies $[15,55]$.

\subsubsection{Neural Network Radial Basis Function (RBF)}

$\mathrm{RBF}$ is an artificial neural network that performs supervised machine learning. It is a more complicated process than a simple linear classifier, and it can analyze a substantial amount of data. RBF is considered an excellent function classifier for spectral reflectance data [56]. Generally, in neural networks, the back-propagation technique is utilized to adjust the weights of the network to improve classification accuracy [57]. In this study, the full dataset was randomly split into three datasets including $70 \%$ training, 20\% testing, and 10\% hold out, based on [58]. The input layers were healthy, asymptomatic, and early and late disease development stages. A holdout cross-validation method was utilized to validate the results. Cross-validation classifies all variables.

\subsubsection{K-Nearest Neighbor (KNN)}

KNN is a widely used machine learning algorithm that works well on simple recognition problems in supervised learning environments [59]. It is one of the most straightforward classification algorithms, and it can be used for classification and regression predictive problems providing highly competitive results. In $\mathrm{KNN}$, each neighbor is assigned with a contribution weight so that the nearer neighbors contribute more than the distant ones to the average. The " $\mathrm{K}$ " in KNN denotes the number of the nearest neighbors used in the classification. In general, KNN is easy to use and works well with little prior knowledge of the data distribution [60]. Euclidean distance strategy is the most common method to calculate the variations between samples characterized as vector inputs [61]. In this study, the training data set was $70 \%$, and $30 \%$ was used as testing data.

\section{Results}

\subsection{Indoor Imaging Technique}

The indoor imaging technique that was used in this study allowed us to determine spectral signatures of leaves with each disease development stage in laboratory conditions (Figure 5). Figure 5 shows the spectral signatures of the four categories-healthy, asymptomatic, early, and late disease development stages - for leaves in laboratory conditions. The healthy leaves presented a higher reflectance in the green bands $(548 \mathrm{~nm})$ with a peak of $23 \%$ reflectance. In the same band, the asymptomatic stage produced a $19 \%$ peak and the early symptomatic stage a peak of $17 \%$. The reflectance curves of those three stages were similar. In the red bands, later stages showed a higher reflectance (Figure 5).

The classification rates of healthy and canker-infected citrus tissues (leaves and fruits) were determined (Figure 6). All classification rates were high in all categories (between healthy and non-healthy leaves and fruit), with the exception of the classification between healthy and asymptomatic immature fruit (Figure 6b). The RBF classifications have higher classifications than the KNN in all categories (Figure 6). The most critical classification determined was between a healthy and an asymptomatic leaf, which achieved $96 \%$ and $94 \%$ accuracy with the RBF and KNN methods, respectively. These classification accuracies were considered high enough to distinguish between healthy and asymptomatic stages. 


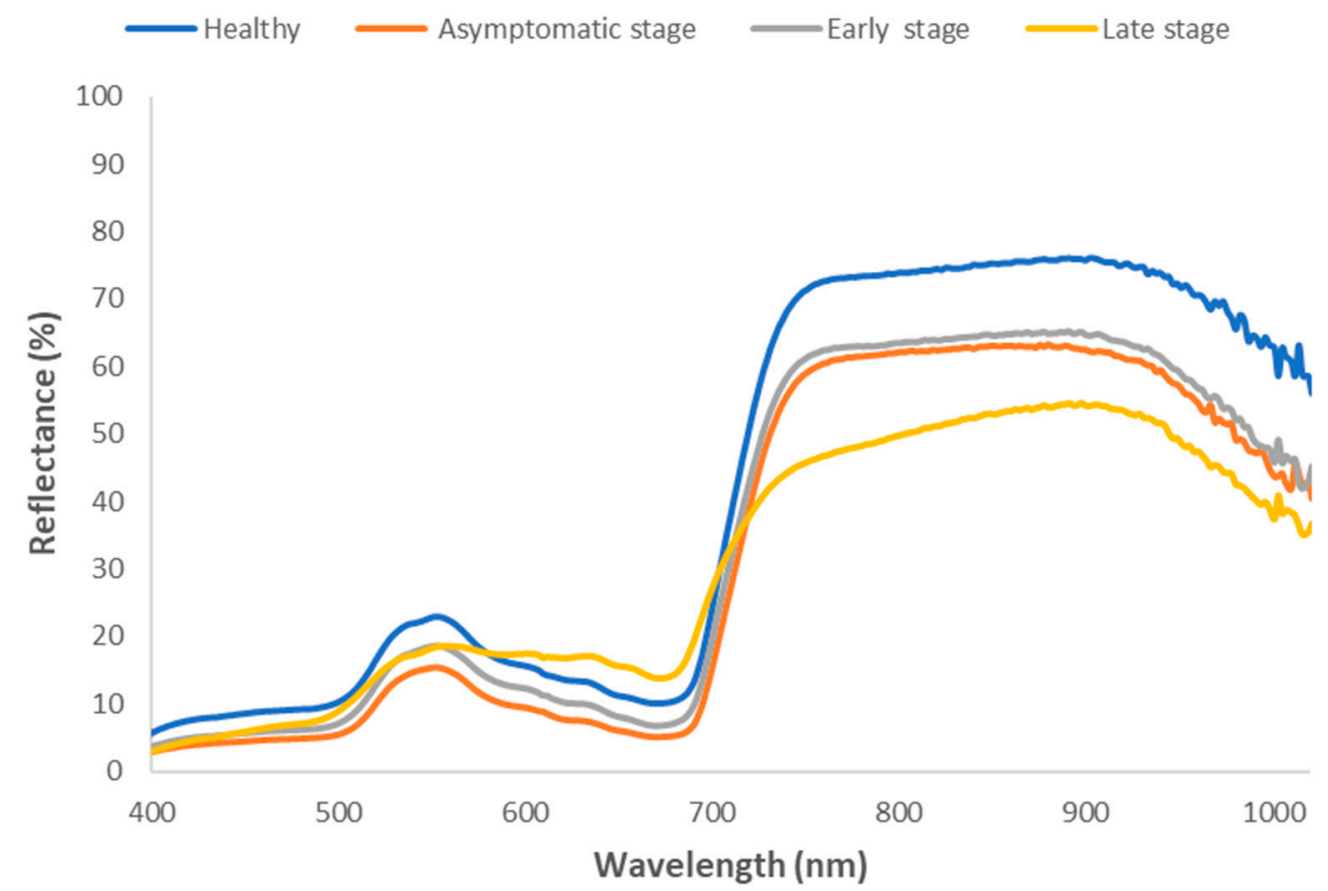

Figure 5. The spectral signatures of the four categories-healthy, asymptomatic, early, and late disease development stages-for leaves in laboratory conditions. Spectral reflectance signatures produced by the indoor leaf analysis are shown with different colored lines.

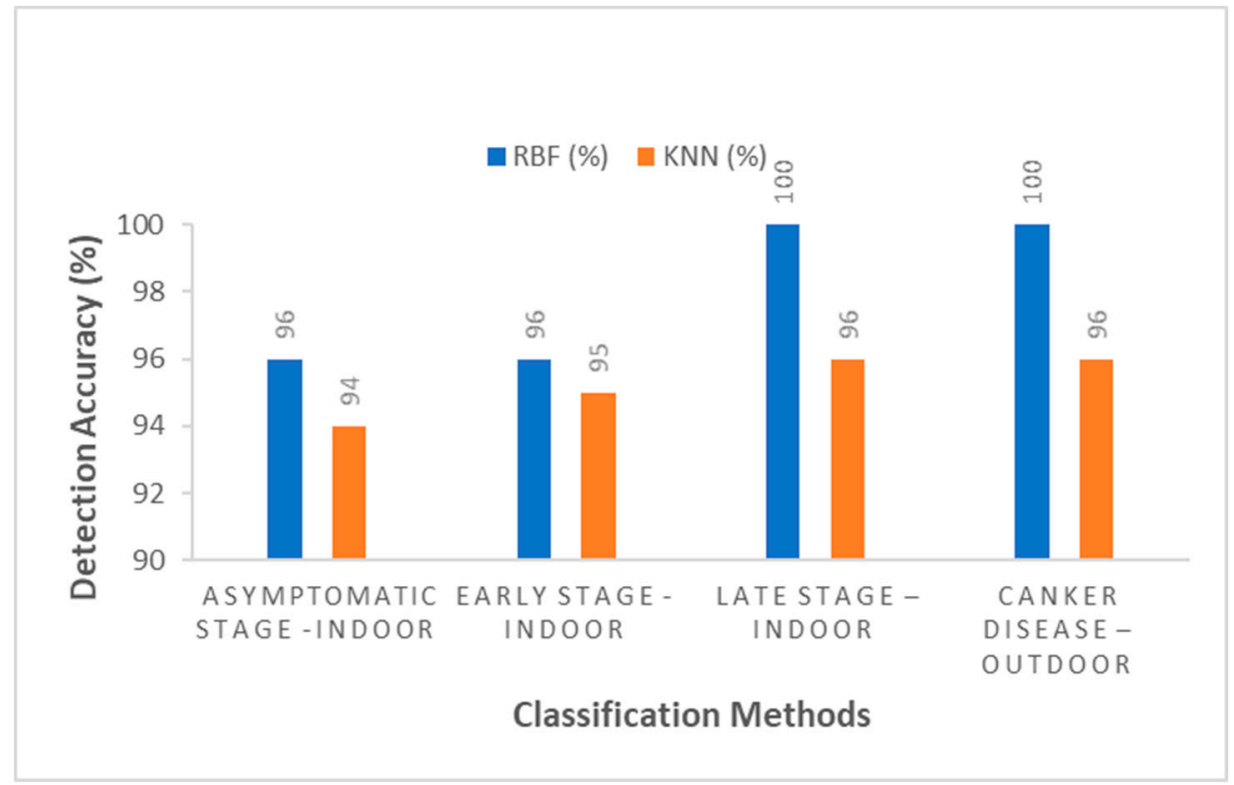

(a)

Figure 6. Cont. 


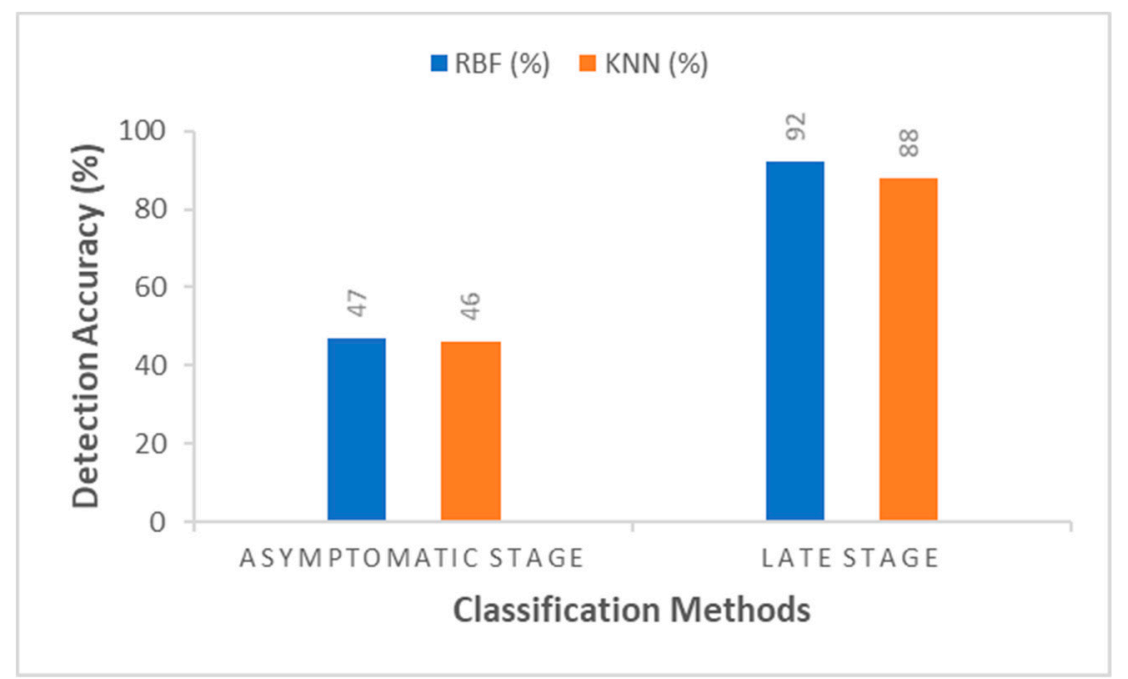

(b)

Figure 6. The classification rates of healthy and canker-infected citrus tissues (leaves and fruits) determined by the hyperspectral classification methods (radial basis function, RBF; and K-nearest neighbor, KNN) between different canker disease stages (healthy, asymptomatic, early, and late stage) for (a) leaves (indoor and outdoor) and (b) immature (green) fruits (indoor).

The spectral structure of immature (green) fruit in a healthy stage and in two disease developmental stages (asymptomatic and late stage) are presented in Figure 7. The late stage signature showed higher reflectance than the other two stages in the visible range and dropped down in $700 \mathrm{~nm}$ (Figure 7). The late disease developmental stage showed a different reflectance slope in red and red edge bands from all other stages. Healthy and asymptomatic signatures did not show significant differences in the visible and NIR. The RBF and KNN recorded low classification values when comparing healthy and asymptomatic fruit ( $47 \%$ and $46 \%$, respectively); so, it was not possible to distinguish between healthy and asymptomatic immature fruit using the proposed technique (Figure 6b). Nevertheless, it was possible to separate healthy fruit from those fruits with late disease developmental stage (Figure 6b).

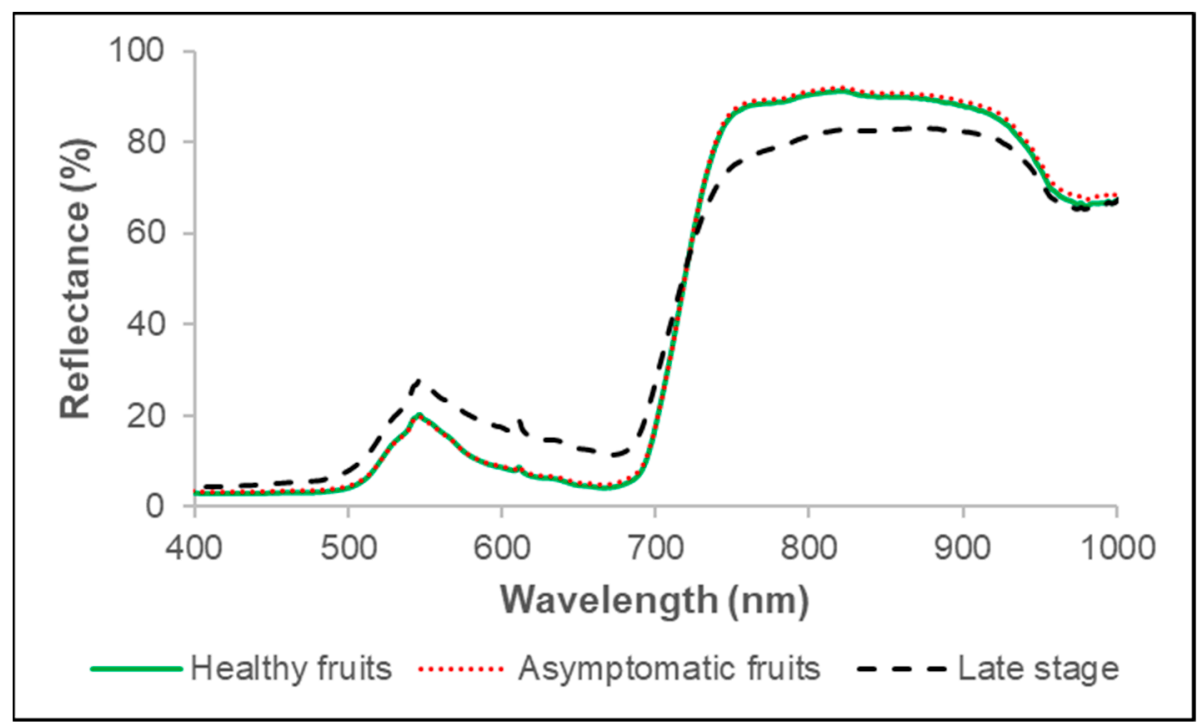

Figure 7. The spectral structure of immature (green) fruit in a healthy stage and in two disease developmental stages. The hyperspectral signature of Sugar Belle immature fruit in healthy, asymptomatic, and late canker stages are shown with different colored lines. 


\subsection{UAV-Based Imaging Technique (Outdoor)}

We were able to measure the spectral reflectance of healthy citrus trees and trees infected with canker disease with the UAV-based imaging technique (Figure 8). The spectral signature of the healthy trees was similar to the signature of the healthy leaves produced by the indoor imaging system. A peak was observed in the green band $(554 \mathrm{~nm})$ with a reflectance value of $31 \%$. The classification accuracy, between healthy and canker-infected citrus trees, with the UAV-based imaging technique was 100\% and $96 \%$ using the RBF and KNN methods, respectively (Figure 6a). Regions of interest (RoIs) were collected randomly from the canopy of the tree without targeting specific areas. The severity of canker disease and the reflectance values varied among the canopy as both were dependent of the light conditions. Because leaf pigment content, stoma damage, water content, and leaf cell structure affects the light reflectance, the spectral reflectance of canker-infected trees shifted down in both visible and near-infrared bands. Thus, the chlorophyll content of the infected plants was low in both indoor and outdoor analysis.

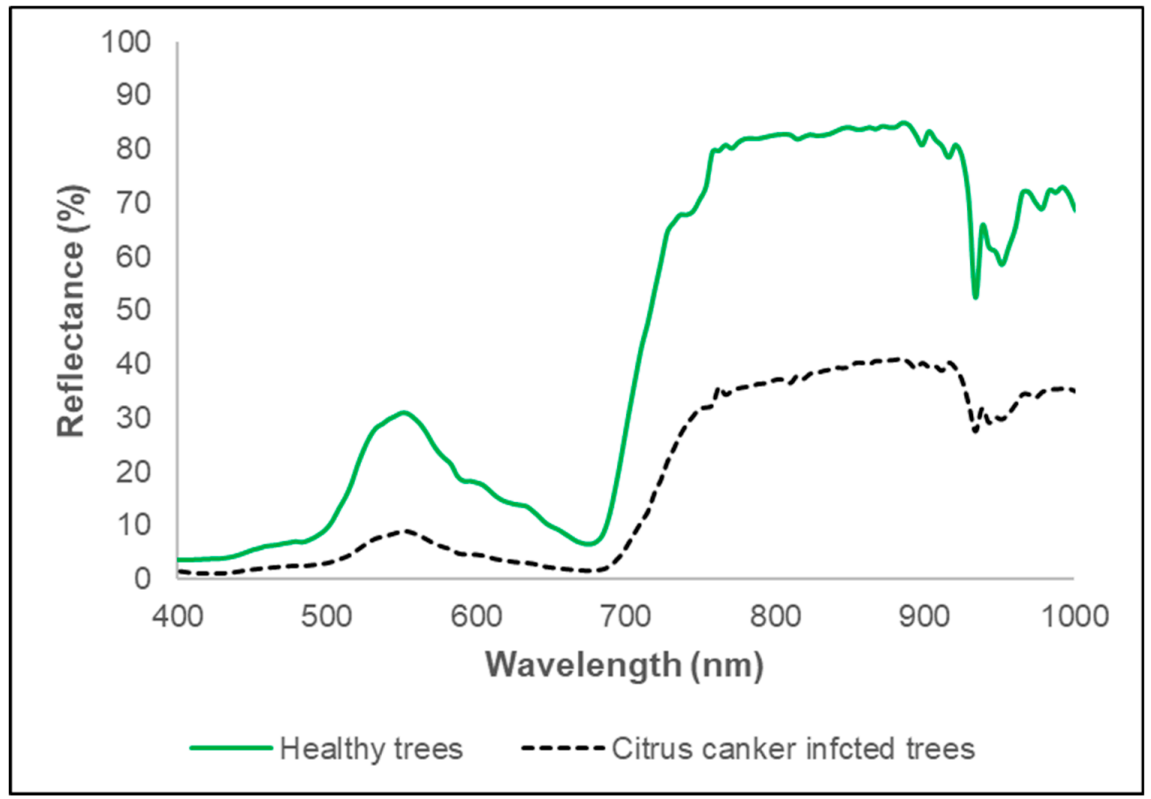

Figure 8. Measurement of the spectral reflectance of healthy citrus trees and trees infected with canker disease. Hyperspectral signatures of healthy trees and canker-infected trees were generated by the UAV-based imaging technique.

\subsection{Vegetation Indices}

The maximum classification accuracy for indoor and outdoor conditions using vegetation indices and the RBF and KNN methods for detection of healthy and different canker disease stages (asymptomatic, early, and late stage) were determined (Figure 9). Using the RBF method, the highest classifications were achieved by comparing healthy leaves with late-stage canker-infected leaves in indoors (100\% using the WI, PRI, GNDVI, and RARSb indices), and healthy leaves with asymptomatic and early-stage canker-infected leaves in indoors (94\% with the WI index and 96\% with the PRI index, respectively) (Figures 9 and 10). The KNN method achieved slightly lower classification accuracies than the RBF, except when comparing leaves in healthy and asymptomatic stages in which similar accuracy with the RBF method (94\%) was obtained (Figure 9). Therefore, the RBF method was chosen to further analyze the classification accuracy though by using only 12 of the 31 proposed VIs that yielded higher classification accuracies (Figure 10). The higher classifications that were obtained when comparing healthy with asymptomatic leaves were by the WI (100\%), NWI 2 (98\%), and SR761 (94\%) (Figure 10a); when comparing healthy with early disease stage leaves were by the PRI (100\%), WI (98\%), NWI2 (95\%), and RVS1 (95\%) (Figure 10b); and when comparing healthy with late disease stage leaves were by the WI (100\%), PRI (100\%), GNDVI (100\%), 
RARSb (96\%), and SIPI (96\%) (Figure 10c). Thus, the WI index can be used to accurately identify healthy leaves apart from all other categories and detect citrus canker. Figure $10 \mathrm{~d}$ presents the classification results of the UAV-based imaging technique, using the RBF method, for each VI. Based on these results, the VIs that could be used to classify healthy vs. canker-infected citrus trees with around $100 \%$ classification accuracy were the ARI $(100 \%)$ and TCARI $(96 \%) 1$. Figure 11 compares the values of some of the most significant VIs (as an example) in different plant conditions (healthy, asymptomatic stage, and early and late disease development stage) for citrus canker detection in both indoor and outdoor conditions $(\rho>F<0.0001)$. The most significant VIs in indoor conditions were the WI and PRI (Figure 11a,b), whereas the ARI was in outdoor conditions (Figure 11c).

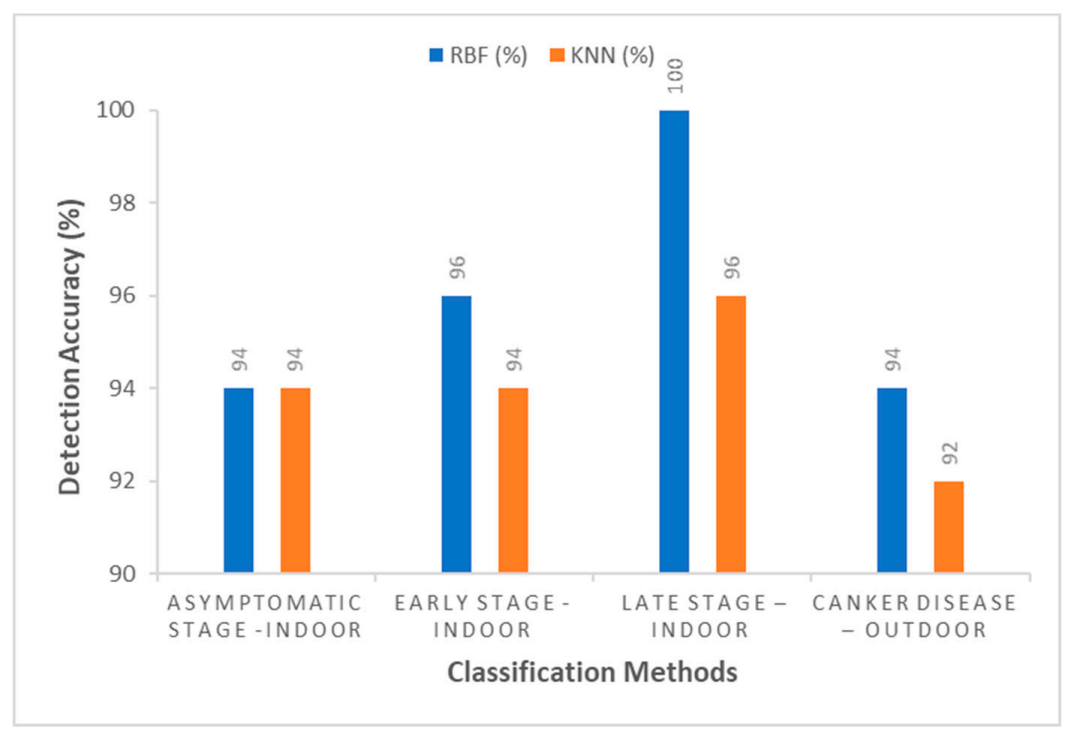

Figure 9. Determination of classification accuracies for indoor and outdoor conditions using vegetation indices and the RBF and KNN methods for the detection of citrus canker. The maximum classification accuracies for indoor and outdoor conditions for healthy vs. different canker disease stages (asymptomatic, early and late stage) are indicated.

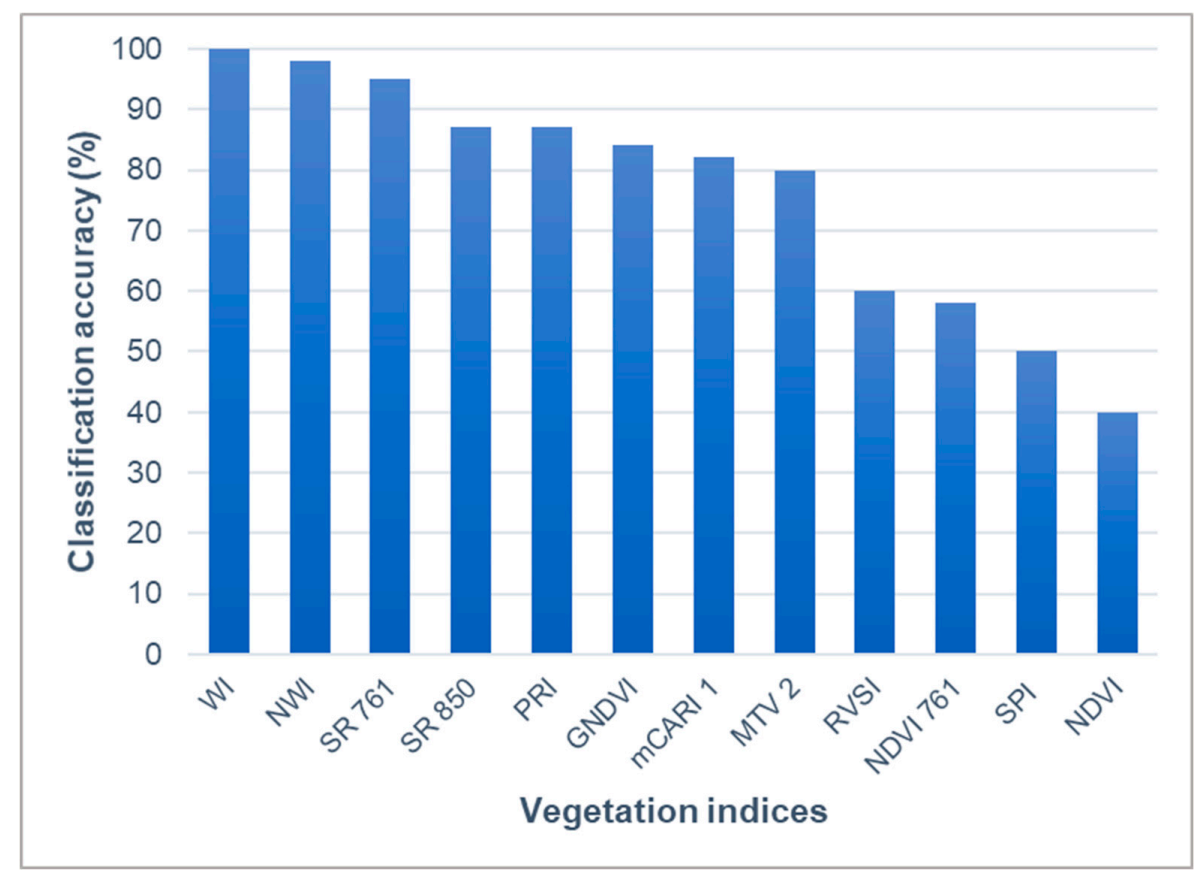

(a)

Figure 10. Cont. 


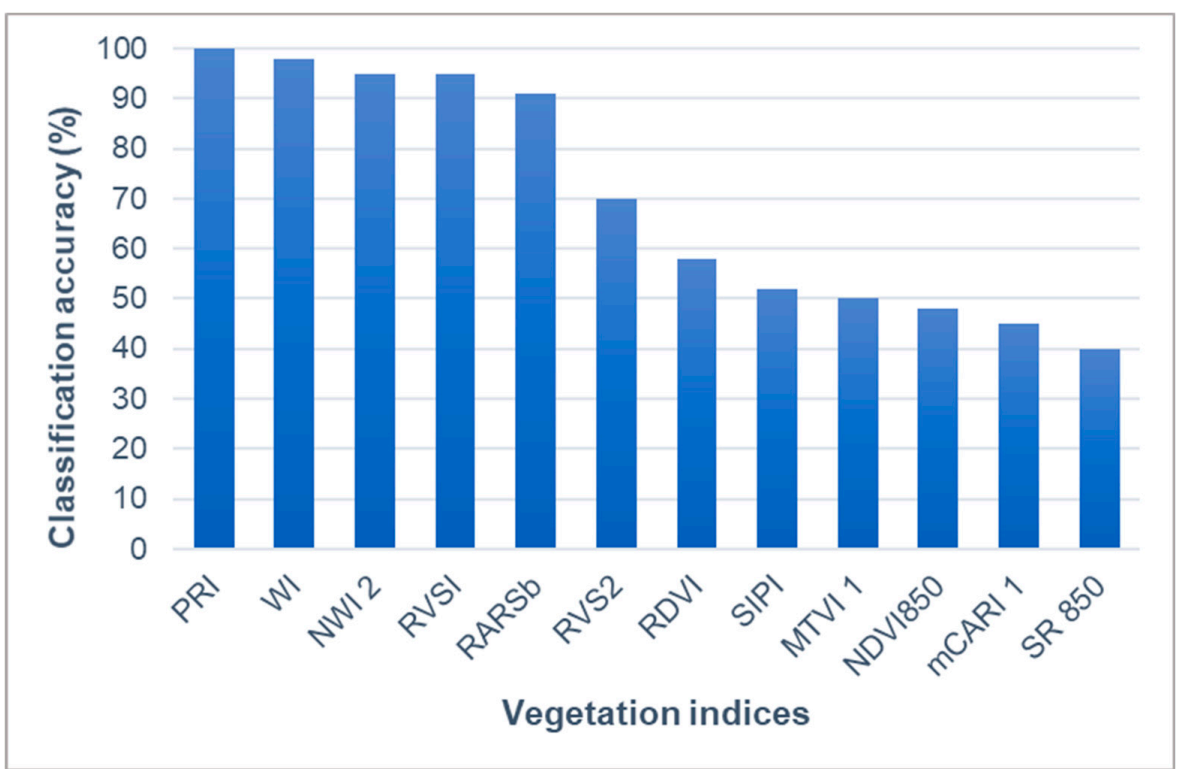

(b)

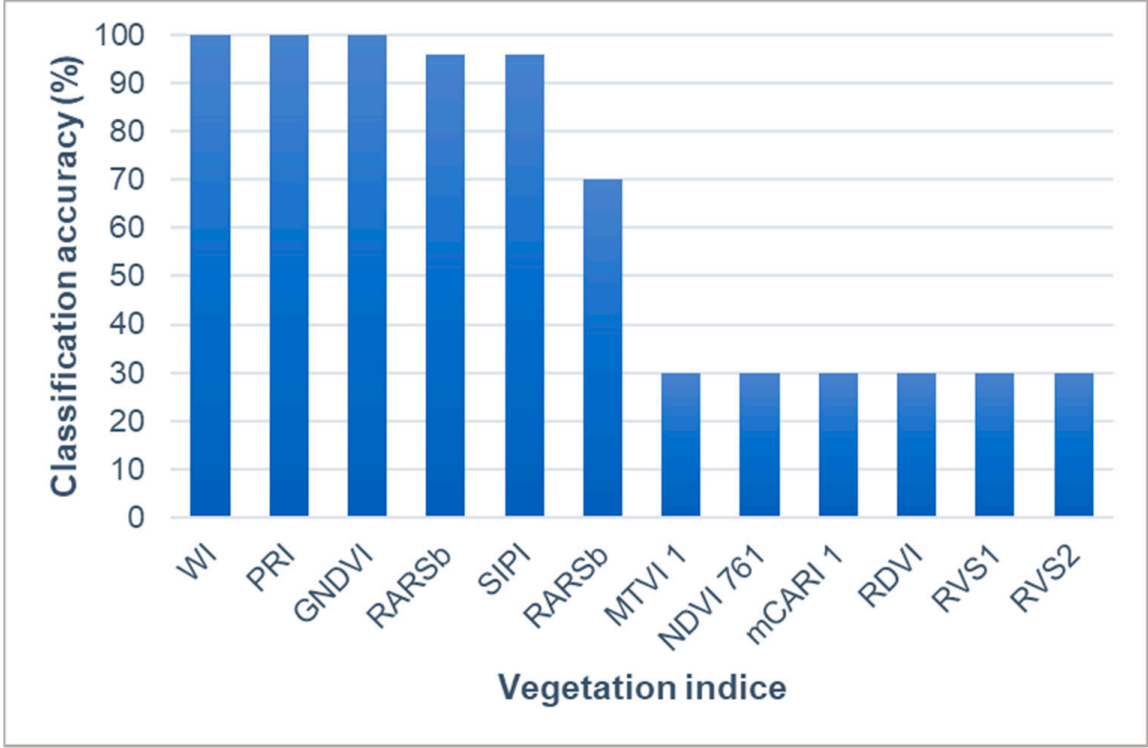

(c)

Figure 10. Cont. 


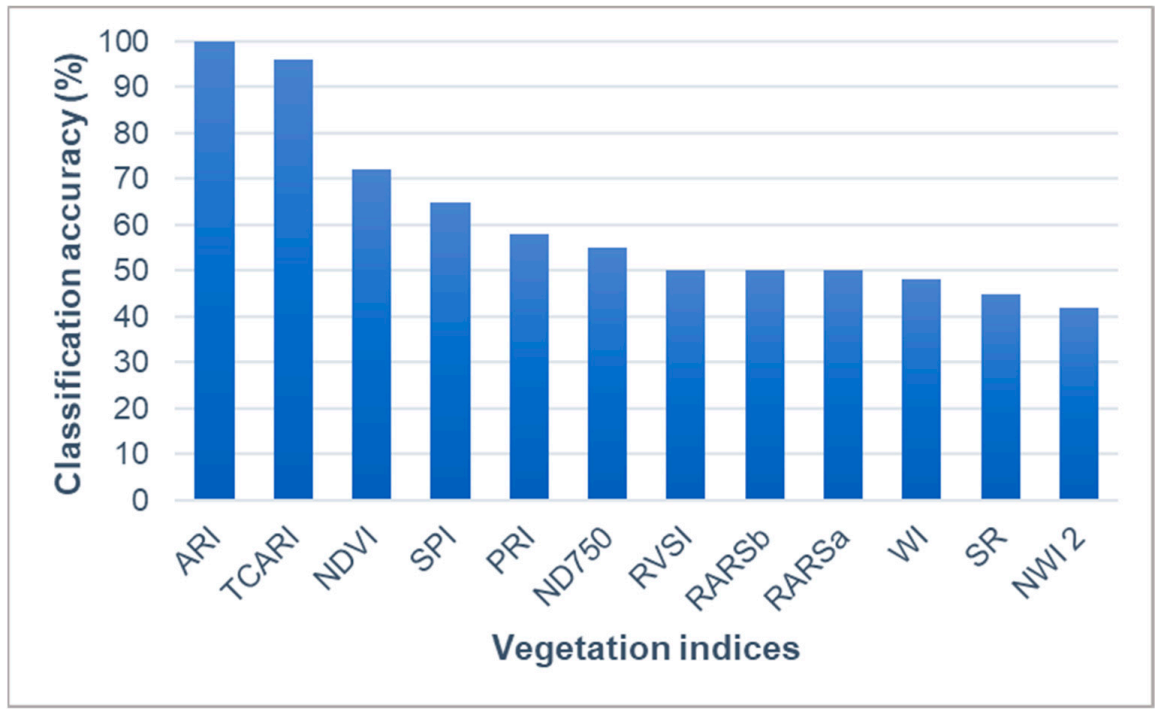

(d)

Figure 10. Classification accuracy of the VIs using the RBF method to detect citrus canker. VIs that were able to detect the canker on leaves of (a) healthy vs. asymptomatic stage (indoors), (b) healthy vs. early stage (indoors), (c) healthy vs. late stage (indoors), and (d) healthy vs. canker-infected trees using the UAV-based imaging technique (outdoor) are shown.

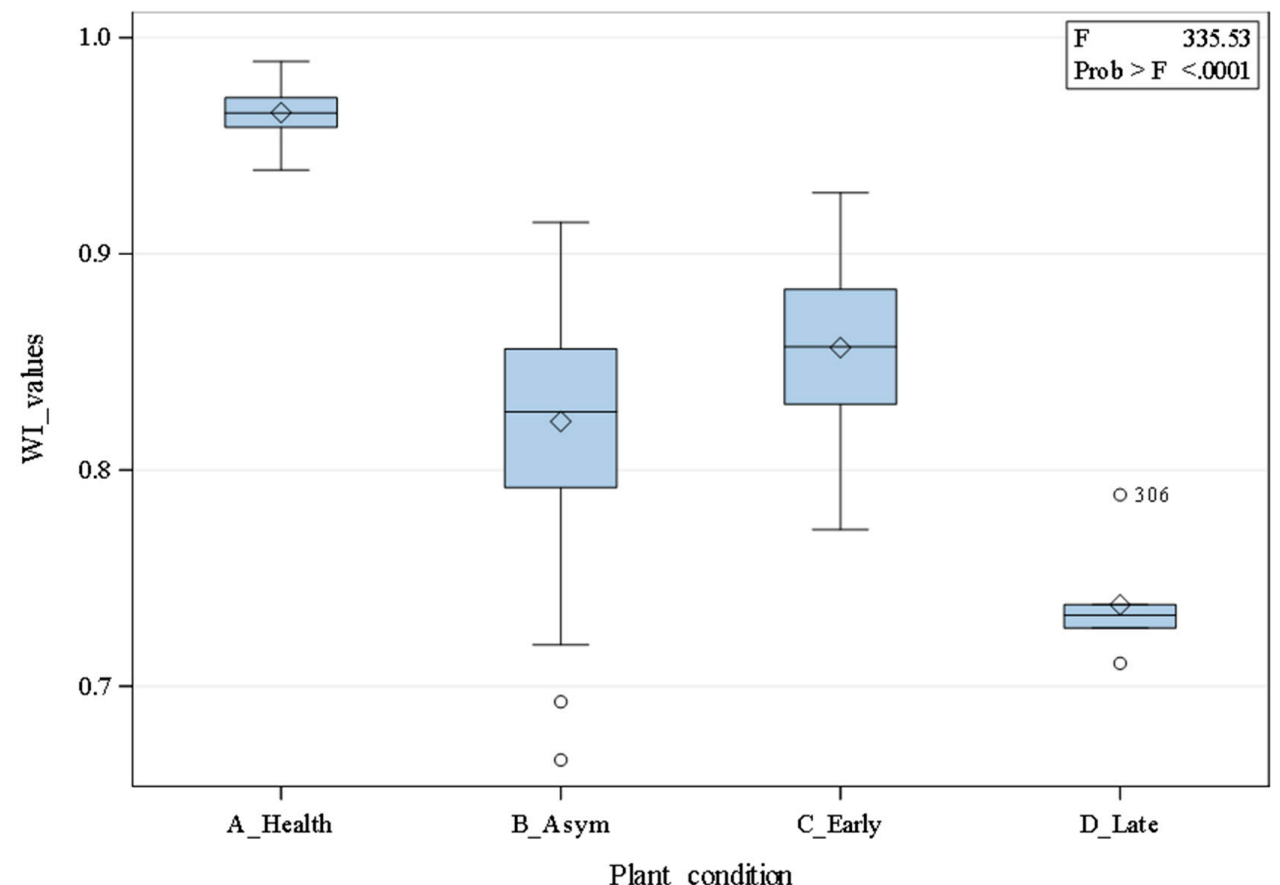

(a)

Figure 11. Cont. 


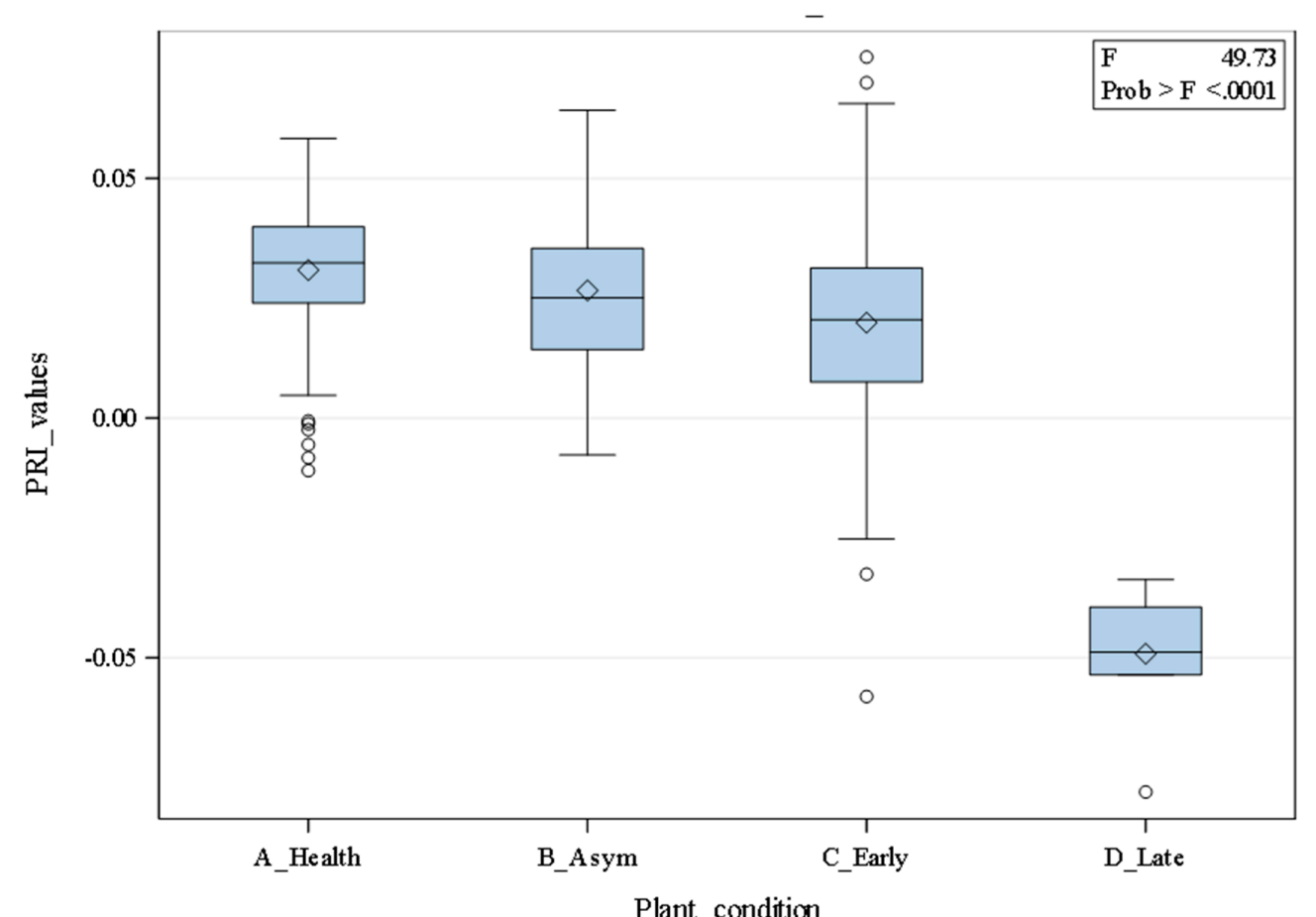

(b)

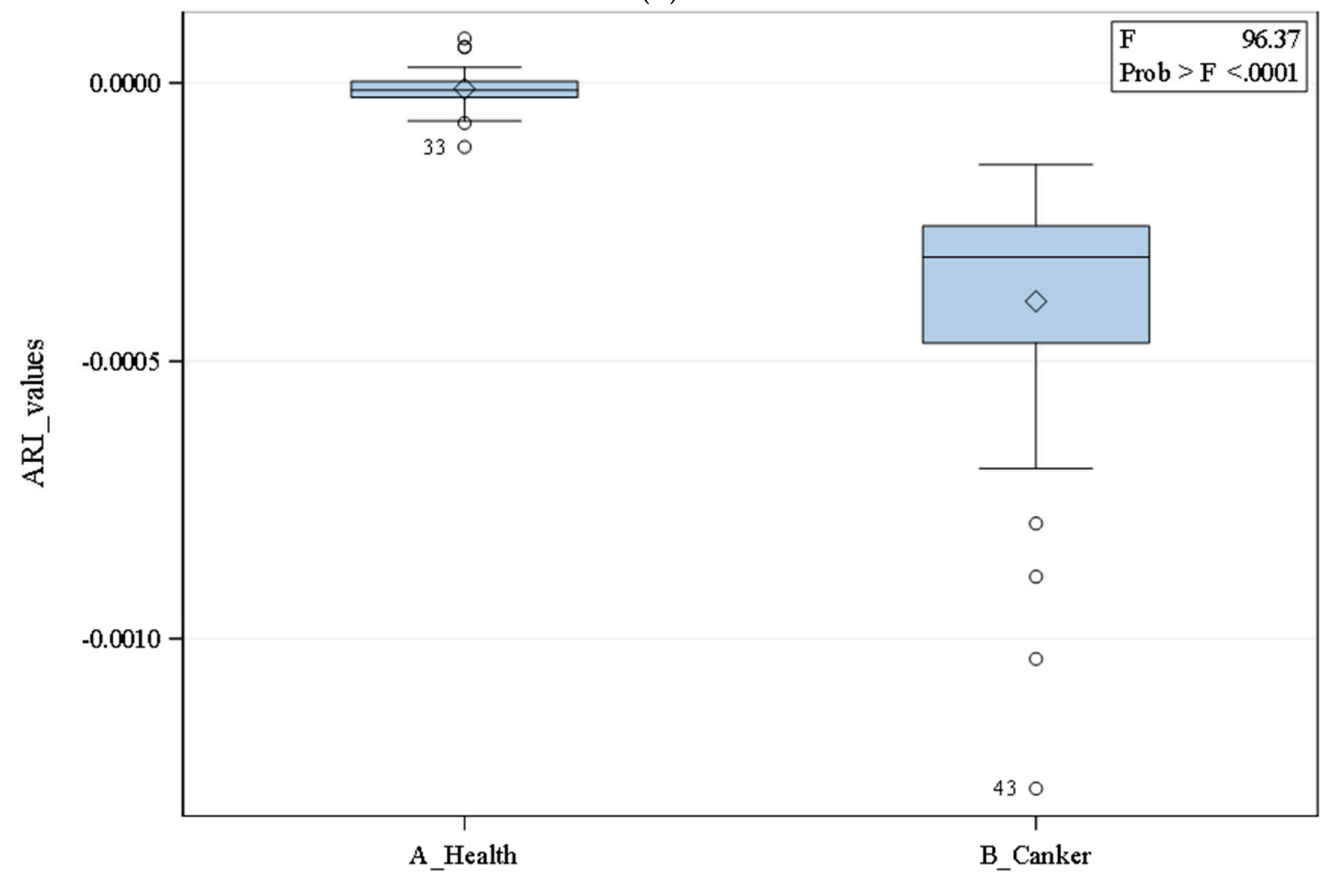

Plant_condition

(c)

Figure 11. Comparison of the VI values in different plant conditions (healthy, asymptomatic stage, and early and late disease developmental stage) for citrus canker detection in both indoor and outdoor conditions. Most significant vegetation index values (for citrus canker disease detection) and their standard deviation in different plant conditions of (a) Water Index (WI) in laboratory conditions, (b) Photochemical Reflectance Index (PRI) in laboratory conditions, and (c) Anthocyanin Reflectance Index (ARI) in field conditions (UAV-based) are shown. 


\section{Discussion}

The indoor imaging technique that we developed in this study allowed us to determine the spectral signatures of leaves with each disease development stage in laboratory conditions (Figure 5). In a healthy plant's signature, the red bands usually showed high absorbance (Figure 5). In this band, leaves in late disease development stages have had pigment reduction, which affected the spectral reflectance. Leaves in healthy and asymptomatic stages did not show any visual differences because the chlorophyll concentration was higher than in late disease development stage. However, the asymptomatic stage is a crucial stage for detecting a disease. Any delay on disease detection might affect a tree's health or even kill them in some situations [62-64]. The canker lesions on leaves in late disease development stage turns brown, the edges appear water-soaked, and it develops a yellow halo. Therefore, the reduction of water content and chlorophyll concentration might affect the spectral reflectance in the visible range $[65,66]$. Consistent with our results, Penuelas et al. [44] confirmed that the red edge peak $(680-780 \mathrm{~nm})$ is an excellent indicator for detecting chlorophyll content and water stress.

Detecting diseases at an early stage (before visual symptoms appear) is very critical for successful mitigation measures (e.g., chemical, or similar, applications) [67]. In our study, in near infrared (NIR) range, healthy leaves appeared different from all other categories (Figure 5), primarily in the red edge $(700 \mathrm{~nm})$. The NIR range of asymptomatic and early disease stages was slightly shifted down. They were very close to each other in the red edge, while late disease stages showed a lower reflectance in the NIR range at 700-950 $\mathrm{nm}$. It is essential to distinguish the disease in an asymptomatic stage before developing and spreading to the entire grove $[68,69]$. Several other studies confirmed that damages in leaves could cause changes in the condition of leaf cells, which leads to the differences in spectral signature in the NIR range (between healthy and diseased leaves). Detecting canker disease in early stage would reduce the management costs by optimizing pesticide applications, which in turn will reduce labor costs. In addition to this, optimization of pesticide applications would reduce any negative effect to the environment and human health [70]. In our experiments and in laboratory conditions, the classification accuracy between healthy and asymptomatic leaves, which is the most critical moment in detecting a disease, was very high ( $96 \%$ with the RBF method; Figure 6$)$, making the proposed technique a valuable tool for early canker disease detection.

It was not possible to distinguish between healthy and asymptomatic immature (green) fruit (in the laboratory); the classification accuracy of the proposed technique was low (47\% with the RBF method, Figure $6 b$ ). However, the proposed technique successfully distinguished healthy from late disease development stage on immature fruit (Figure 6b). In the past, several methods have been developed to detect canker on mature citrus fruit [24,31], but to the best of our knowledge, we are the first to develop a technique to detect canker on immature (green) citrus fruit.

In the field, the UAV-based imaging technique that we have developed successfully distinguished healthy and canker-infected citrus trees with a 100\% classification accuracy using the RBF method (Figure 6a). Several other studies also used a UAV-based imaging approach to detect other diseases in early stages [71,72] and evaluate individual tree health status [17]. For example, Garcia-Ruiz [71] utilized a multispectral camera to identify Huanglongbing (HLB) disease in citrus and compared the results between images acquired by UAV and images captured by an aircraft; the UAV classification results were higher $(67-85 \%)$ and had a better resolution than the aircraft classification $(61-74 \%)$. However, and to the best of our knowledge, we are the first to develop an UAV-based technique to detect citrus canker disease on citrus trees in the grove.

When bacteria attack a plant, some changes might occur to the leaves' pigment content. This will certainly affect the photosynthesis process. As a result, the leaves color would change or some lesion might show up (as a result of pathogen infection). These symptoms would affect light reflectance that can be measured in a remote sensing technique. Therefore, vegetation indices (VIs) have been developed to enhance plant characteristic information, such as the properties of an object, by calculating 
the ratio of two or more spectral bands. For example, the normalized difference vegetation index (NDVI) uses the near-infrared (NIR) and red (R) channels as follows: (NIR-R)/(NIR+R) [73,74].

Finally, we found that it was possible to use VIs to detect citrus canker and distinguish it from other disorders in both indoor and outdoor conditions. Here, the Water Index (WI), one of the 31 VIs used in this study, allowed us to accurately distinguish healthy leaves from all other categories and detect citrus canker (Figure 10a-c). Additionally, two other VIs used, the Anthocyanin Reflectance Index (ARI) and Transform Chlorophyll Absorption in Reflectance Index (TCARI 1), with the RBF method, accurately classified healthy from canker-infected citrus trees in the grove conditions (UAV-based technique, Figure 10d). By analyzing the values of these most significant VIs in different conditions, it was observed that the values of the healthy trees have had the significantly highest values $(\rho>F<0.0001)$ than those of diseased trees (Figure 11). In previous studies, it was also found that the water status, water stress, and canopy structure were affected first after a disease infection [75,76], and thus, these indices can be used to identify phenotypical changes and detect diseased trees.

\section{Conclusions}

The indoor (laboratory conditions) detection technique was able to detect canker-infected citrus leaves in asymptomatic, early, and late disease developmental stages, and the outdoor (UAV-based) detection technique was able to identify canker-infected citrus trees accurately. Additionally, in the laboratory, the proposed technique accurately identified canker-infected immature (green) fruit (early and late disease development stages) and distinguished them from healthy fruit. However, the detection accuracy of canker-infected immature fruit in the asymptomatic stage was low $(47 \%)$, and as a consequence, immature fruit was not a reliable tissue for early detection of canker. Higher classifications were achieved by the RBF method (about $96 \%$ for healthy vs. asymptomatic and early stage, and $100 \%$ for healthy vs. late stage, for both leaves and fruit). Furthermore, it was found that several VIs can be used to precisely detect canker-infected citrus plants. For the indoor imaging technique, the WI index achieved high classification accuracies when comparing healthy leaves with all other categories, and for the UAV-based imaging technique, the ARI and TCARI 1 were the most common indices that were able to detect infected canker plants accurately. The developed imaging techniques would provide valuable tools for identifying citrus canker even in an asymptomatic stage. The UAV-based imaging technique can be utilized to detect canker-infected trees and cover large areas in a short time and with a low-cost. Since both ARI and TCARI 1 indices can be measured with a multispectral camera, an inexpensive UAV equipped with a multispectral imaging system can be used for rapid citrus canker detection in the field.

Author Contributions: Conceptualization, J.A. and Y.A.; methodology, J.A., O.B., and Y.A.; validation, J.A., Y.A. and O.B.; formal analysis, J.A.; investigation, J.A.; resources, Y.A. and O.B.; data curation, J.A.; writing-original draft preparation, J.A.; writing—review and editing, J.A., O.B., and Y.A.; visualization, J.A.; supervision, Y.A. and O.B.; project administration, Y.A.

Funding: This research received no external funding.

Acknowledgments: The authors wish to thank everybody who has helped with completing this work: Sri Charan Kakarla for collecting images, the plant pathology lab for conducting the PCR analysis, Timothy Willis and Ahmed Omer for leaves collection, and John Landau for language editing.

Conflicts of Interest: The authors declare no conflict of interest.

\section{References}

1. Bock, C.H.; Parker, P.E.; Gottwald, T.R. Effect of stimulated wind-driven rain on duration and distance of dispersal of Xanthomonas axonompodis pv. citri from canker-infected citrus trees. Plant Dis. 2005, 89, 71-80. [CrossRef] [PubMed]

2. Hartung, J.S.; Daniel, J.F.; Pruvost, O.P. Detection of anthomonas-campestris pv. citri by the polymerase chain-reaction method. Appl. Environ. Microbiol. 1993, 59, 1143-1148. [PubMed] 
3. Duan, S.; Jia, H.G.; Pang, Z.Q.; Teper, D.; White, F.; Jones, J.; Zhou, C.Y.; Wang, N. Functional characterization of the citrus canker susceptibility gene CsLOB1. Mol. Plant Pathol. 2018, 19, 1908-1916. [CrossRef] [PubMed]

4. Bock, C.H.; Graham, J.H.; Gottwald, T.R.; Cook, A.Z.; Parker, P.E. Wind speed and wind-associated leaf injury affect severity of citrus canker on Swingle citrumelo. Eur. J. Plant Pathol. 2010, 128, 21-38. [CrossRef]

5. Gottwald, R.T.; Graham, H.J.; Schubert, T.S. Citrus canker: the pathogen and its impact. Online. Plant Health Progress. 2002. [CrossRef]

6. Graham, H.J.; Gottwald, R.T.; Cubero, J.; Achor, D. Xanthomonas axonopodis pv. citri: Factors affecting successful eradication of citrus canker. Mol. Plant Pathol. 2004, 5, 1-5. [CrossRef]

7. Park, D.S.; Hyun, J.W.; Park, Y.J.; Kim, J.S.; Kang, H.W.; Hahn, J.H.; Go, S.J. Sensitive and specific detection of Xanthomonas axonopodis pv. citri by PCR using pathovar specific primers based on hrpW gene sequences. Microbiol. Res. 2006, 161, 145-149. [CrossRef]

8. Graham, J.H.; Leite, R.P. Lack of control of citrus canker by induced systemic resistance compounds. Plant Dis. 2004, 88, 745-750. [CrossRef]

9. Partel, V.; Kakarla, C.; Ampatzidis, Y. Development and evaluation of a low-cost and smart technology for precision weed management utilizing artificial intelligence. Comput. Electron. Agric. 2019, 157, 339-350. [CrossRef]

10. Partel, V.; Nunes, L.; Stansley, P.; Ampatzidis, Y. Automated vision-based system for monitoring Asian citrus psyllid in orchards utilizing artificial intelligence. Comput. Electron. Agric. 2019, 162, 328-336. [CrossRef]

11. Ashourloo, D.; Aghighi, H.; Matkan, A.A.; Mobasheri, M.R.; Rad, A.M. An investigation into machine learning regression techniques for the leaf rust disease detection using hyperspectral measurement. IEEE J. Sel. Top. Appl. Earth Obs. Remote Sens. 2016, 9, 4344-4351. [CrossRef]

12. Zhang, Y.; Lee, W.S.; Li, M.Z.; Zheng, L.H.; Ritenour, M.A. Non-destructive recognition and classification of citrus fruit blemishes based on ant colony optimized spectral information. Postharvest Biol. Technol. 2018, 143, 119-128. [CrossRef]

13. Behmann, J.; Acebron, K.; Emin, D.; Bennertz, S.; Matsubara, S.; Thomas, S.; Bohnenkamp, D.; Kuska, M.T.; Jussila, J.; Salo, H.; et al. Specim IQ: Evaluation of a new, miniaturized handheld hyperspectral camera and its application for plant phenotyping and disease detection. Sensors 2018, 18, 441. [CrossRef]

14. Abdulridha, J.; Ampatzidis, Y.; Ehsani, R.; de Castro, A.I. Evaluating the performance of spectral features and multivariate analysis tools to detect laurel wilt disease and nutritional deficiency in avocado. Comput. Electron. Agric. 2018, 155, 203-211. [CrossRef]

15. Lu, J.Z.; Ehsani, R.; Shi, Y.Y.; Abdulridha, J.; de Castro, A.I.; Xu, Y.J. Field detection of anthracnose crown rot in strawberry using spectroscopy technology. Comput. Electron. Agric. 2017, 135, 289-299. [CrossRef]

16. Maes, W.H.; Steppe, K. Perspectives for remote sensing with unmanned aerial vehicles in precision agriculture. Trends Plant Sci. 2019, 24, 152-164. [CrossRef]

17. Ampatzidis, Y.; Partel, V. UAV-based high throughput phenotyping in citrus utilizing multispectral imaging and artificial intelligence. Remote Sens. 2019, 11, 410. [CrossRef]

18. Zhang, J.; Virk, S.; Porter, W.; Kenworthy, K.; Sullivan, D.; Schwartz, B. Applications of unmanned aerial vehicle based imagery in turfgrass field trials. Front. Plant Sci. 2019, 10, 279. [CrossRef]

19. Albetis, J.; Jacquin, A.; Goulard, M.; Poilve, H.; Rousseau, J.; Clenet, H.; Dedieu, G.; Duthoit, S. On the potentiality of UAV multispectral imagery to detect flavescence doree and grapevine trunk diseases. Remote Sens. 2019, 11, 23. [CrossRef]

20. Albetis, J.; Duthoit, S.; Guttler, F.; Jacquin, A.; Goulard, M.; Poilve, H.; Feret, J.B.; Dedieu, G. Detection of flavescence doree grapevine disease using unmanned aerial vehicle (UAV) multispectral imagery. Remote Sens. 2017, 9, 308. [CrossRef]

21. Kerkech, M.; Hafiane, A.; Canals, R. Deep leaning approach with colorimetric spaces and vegetation indices for vine diseases detection in UAV images. Comput. Electron. Agric. 2018, 155, 237-243. [CrossRef]

22. Dash, J.P.; Pearse, G.D.; Watt, M.S. UAV multispectral imagery can complement satellite data for monitoring forest health. Remote Sens. 2018, 10, 1216. [CrossRef]

23. Liu, Q.; Song, H.; Liu, G.; Huang, C.; Li, H. Evaluating the potential of multi-seasonal CBERS-04 imagery for mapping the quasi-circular vegetation patches in the Yellow River delta using random forest. Remote Sens. 2019, 11, 1216. [CrossRef]

24. Qin, J.; Burks, T.F.; Ritenour, M.A.; Bonn, W.G. Detection of citrus canker using hyperspectral reflectance imaging with spectral information divergence. J. Food Eng. 2009, 93, 183-191. [CrossRef] 
25. Weng, H.Y.; Lv, J.W.; Cen, H.Y.; He, M.B.; Zeng, Y.B.; Hua, S.J.; Li, H.Y.; Meng, Y.Q.; Fang, H.; He, Y. Hyperspectral reflectance imaging combined with carbohydrate metabolism analysis for diagnosis of citrus Huanglongbing in different seasons and cultivars. Sens. Actuators B Chem. 2018, 275, 50-60. [CrossRef]

26. Sharif, M.; Khan, M.A.; Iqbal, Z.; Azam, M.F.; Lali, M.I.U.; Javed, M.Y. Detection and classification of citrus diseases in agriculture based on optimized weighted segmentation and feature selection. Comput. Electron. Agric. 2018, 150, 220-234. [CrossRef]

27. Zhang, B.H.; Liu, L.S.; Gu, B.X.; Zhou, J.; Huang, J.C.; Tian, G.Z. From hyperspectral imaging to multispectral imaging: Portability and stability of HIS-MIS algorithms for common defect detection. Postharvest Biol. Technol. 2018, 137, 95-105. [CrossRef]

28. Sankaran, S.; Mishra, A.; Maja, J.M.; Ehsani, R. Visible-near infrared spectroscopy for detection of Huanglongbing in citrus orchards. Comput. Electron. Agric. 2011, 77, 127-134. [CrossRef]

29. Mishra, A.R.; Karimi, D.; Ehsani, R.; Lee, W.S. Identification of citrus greening (HLB) using a VIS-NIR spectroscopy technique. Trans. ASABE 2012, 55, 711-720. [CrossRef]

30. Sankaran, S.; Ehsani, R. Comparison of visible near infrared and mid-infrared spectroscopy for classification of Huanglongbing and citrus canker infected leaves. Agric. Eng. Int. CIGR J. 2013, 15, 75.

31. Pourreza, A.; Lee, W.S.; Ritenour, M.A.; Roberts, P. Spectral characteristics of citrus black spot disease. Horttechnology 2016, 26, 254-260.

32. Tanner, M.A.; Everett, C.L.; Youvan, D.C. Molecular phylogenetic evidence for noninvasive zoonotic transmission of Staphylococcus intermedius from a canine pet to a human. J. Clin. Microbiol. 2000, 38, 1628-1631. [PubMed]

33. Penuelas, J.; Pinol, J.; Ogaya, R.; Filella, I. Estimation of plant water concentration by the reflectance water index WI (R900/R970). Int. J. Remote Sens. 1997, 18, 2869-2875. [CrossRef]

34. Haboudane, D.; Miller, J.R.; Pattey, E.; Zarco-Tejada, P.J.; Strachan, I.B. Hyperspectral vegetation indices and novel algorithms for predicting green LAI of crop canopies: Modeling and validation in the context of precision agriculture. Remote Sens. Environ. 2004, 90, 337-352. [CrossRef]

35. Jordan, C.F. Derivation of leaf area index from quality of light on the forest floor. Ecology 1969, 50, 663-666. [CrossRef]

36. Gitelson, A.A.; Merzlyak, M.N. Signature analysis of leaf reflectance spectra: Algorithm development for remote sensing of chlorophyll. J. Plant Physiol. 1996, 148, 494-500. [CrossRef]

37. Gamon, J.A.; Penuelas, J.; Field, C.B. A narrow-waveband spectral index that tracks diurnal changes in photosynthetic efficiency. Remote Sens. Environ. 1992, 41, 35-44. [CrossRef]

38. Chappelle, E.W.; Kim, M.S.; McMurtrey, J.E. Ration analysis of reflectance spectra (RARS)—An algorithm for the remote estimation concentration of chlorophyll-a, chlorophyll-b, and carotenoid soybean leaves. Remote Sens. Environ. 1992, 39, 239-247. [CrossRef]

39. Blackburn, G.A. Spectral indices for estimating photosynthetic pigment concentrations: A test using senescent tree leaves. Int. J. Remote Sens. 1998, 19, 657-675. [CrossRef]

40. Raun, W.R.; Solie, J.B.; Johnson, G.V.; Stone, M.L.; Lukina, E.V.; Thomason, W.E.; Schepers, J.S. In-season prediction of potential grain yield in winter wheat using canopy reflectance. Agron. J. 2001, 93, 131-138. [CrossRef]

41. Penuelas, J.; Baret, F.; Filella, I. Semiempirical indexes to assess carotenoids chlorophyll-a ratio from leaf spectral reflectance. Photosynthetica 1995, 31, 221-230.

42. Penuelas, J.; Filella, I.; Biel, C.; Serrano, L.; Save, R. The reflectance at the $950-970 \mathrm{~nm}$ region as an indicator of plant water status. Int. J. Remote Sens. 1993, 14, 1887-1905. [CrossRef]

43. Barnes, J.D.; Balaguer, L.; Manrique, E.; Elvira, S.; Davison, A.W. A reappraisal of the use of DMSO for the extraction and determination of chlorophylls-A and chlorophylls-B in lichens and higher-plants. Environ. Exp. Bot. 1992, 32, 85-100. [CrossRef]

44. Penuelas, J.; Gamon, J.A.; Fredeen, A.L.; Merino, J.; Field, C.B. Reflectance indexes associated with physiological-changes in nitrogen-limited and water-limited sunflower leaves. Remote Sens. Environ. 1994, 48, 135-146. [CrossRef]

45. Hunt, E.R., Jr.; Rock, B.N. Detection of changes in leaf water content using near- and middle-infrared reflectances. Remote Sens. Environ. 1989, 30, 43-54.

46. Haboudane, D.; Miller, J.R.; Tremblay, N.; Zarco-Tejada, P.J.; Dextraze, L. Integrated narrow-band vegetation indices for prediction of crop chlorophyll content for application to precision agriculture. Remote Sens. Environ. 2002, 81, 416-426. [CrossRef] 
47. Gitelson, A.A.; Kaufman, Y.J.; Stark, R.; Rundquist, D. Novel algorithms for remote estimation of vegetation fraction. Remote Sens. Environ. 2002, 80, 76-87. [CrossRef]

48. Merton, R. Monitoring Community Hysteresis Using Spectral Shift Analysis and the Red-Edge Vegetation Stress Index. In JPL Airborne Earth Science Workshop; NASA, Jet Propulsion Laboratory: Pasadena, CA, USA, 1998.

49. Broge, N.H.; Leblanc, E. Comparing prediction power and stability of broadband and hyperspectral vegetation indices for estimation of green leaf area index and canopy chlorophyll density. Remote Sens. Environ. 2001, 76, 156-172. [CrossRef]

50. Roujean, J.L.; Breon, F.M. Estimating par absorbed by vegetation from bidirectional reflectance measurements. Remote Sens. Environ. 1995, 51, 375-384. [CrossRef]

51. Metternicht, G. Vegetation indices derived from high-resolution airborne videography for precision crop management. Int. J. Remote Sens. 2003, 24, 2855-2877. [CrossRef]

52. Babar, M.A.; Reynolds, M.P.; Van Ginkel, M.; Klatt, A.R.; Raun, W.R.; Stone, M.L. Spectral reflectance to estimate genetic variation for in-season biomass, leaf chlorophyll, and canopy temperature in wheat. Crop Sci. 2006, 46, 1046-1057. [CrossRef]

53. Bausch, W.C.; Duke, H.R. Remote sensing of plant nitrogen status in corn. Trans. ASAE 1996, 39, $1869-1875$. [CrossRef]

54. Gitelson, A.A.; Merzlyak, M.N.; Chivkunova, O.B. Optical properties and nondestructive estimation of anthocyanin content in plant leaves. Photochem. Photobiol. 2001, 74, 38-45. [CrossRef]

55. Omrani, E.; Khoshnevisan, B.; Shamshirband, S.; Saboohi, H.; Anuar, N.B.; Nasir, M. Potential of radial basis function-based support vector regression for apple disease detection. Measurement 2014, 55, 512-519. [CrossRef]

56. Singh, V.; Rao, S.M. Application of image processing and radial basis neural network techniques for ore sorting and ore classification. Miner. Eng. 2005, 18, 1412-1420. [CrossRef]

57. Palmer, S.E. Parallel distributed-processing-Explorations in the microstructure of cognition. Contemp. Psychol. 1987, 32, 925-928. [CrossRef]

58. Barros, A.C.A.; Cavalcanti, G.D.C. Combining global optimization algorithms with a simple adaptive distance for feature selection and weighting. In Proceedings of the IEEE International Joint Conference on Neural Networks (IJCNN 2008), Hong Kong, China, 1-8 June 2008.

59. Abdullah, M.Z.; Guan, L.C.; Azemi, B. Stepwise discriminant analysis for colour grading of oil palm using machine vision system. Food Bioprod. Process. 2001, 79, 223-231. [CrossRef]

60. Swartzla, E.E.; Fukunaga, K. Introduction to statistical pattern recognition. IEEE Trans. Syst. Man Cybern. 1974, MC 4, 238.

61. Weinberger, K.Q.; Saul, L.K. Distance metric learning for large margin nearest neighbor classification. J. Mach. Learn. Res. 2009, 10, 207-244.

62. Abdulridha, J.; Ehsani, R.; de Castro, A. Detection and differentiation between laurel wilt disease, phytophthora disease, and salinity damage using a hyperspectral sensing technique. Agriculture 2016, 6, 56. [CrossRef]

63. Ampatzidis, Y.; De Bellis, L.; Luvisi, A. iPathology: Robotic applications and management of plants and plant diseases. Sustainability 2017, 9, 1010. [CrossRef]

64. Luvisi, A.; Ampatzidis, Y.G.; De Bellis, L. Plant pathology and information technology: Opportunity for management of disease outbreak and applications in regulation frameworks. Sustainability 2016, 8, 831. [CrossRef]

65. Sims, D.A.; Gamon, J.A. Relationships between leaf pigment content and spectral reflectance across a wide range of species, leaf structures and developmental stages. Remote Sens. Environ. 2002, 81, 337-354. [CrossRef]

66. Daughtry, C.S.T.; Walthall, C.L.; Kim, M.S.; de Colstoun, E.B.; McMurtrey, J.E. Estimating corn leaf chlorophyll concentration from leaf and canopy reflectance. Remote Sens. Environ. 2000, 74, 229-239. [CrossRef]

67. Lowe, A.; Harrison, N.; French, A.P. Hyperspectral image analysis techniques for the detection and classification of the early onset of plant disease and stress. Plant Methods 2017, 13, 80. [CrossRef]

68. Sonobe, R.; Sano, T.; Horie, H. Using spectral reflectance to estimate leaf chlorophyll content of tea with shading treatments. Biosyst. Eng. 2018, 175, 168-182. [CrossRef]

69. Frels, K.; Guttieri, M.; Joyce, B.; Leavitt, B.; Baenziger, P.S. Evaluating canopy spectral reflectance vegetation indices to estimate nitrogen use traits in hard winter wheat. Field Crop. Res. 2018, 217, 82-92. [CrossRef] 
70. Patil, J.K.; Kumer, R. Advances in image processing for detection of plant diseases. Adv. Bioinf. Appl. Res. 2011, 12, 135-141.

71. Garcia-Ruiz, F.; Sankaran, S.; Maja, J.M.; Lee, W.S.; Rasmussen, J.; Ehsani, R. Comparison of two aerial imaging platforms for identification of Huanglongbing-infected citrus trees. Comput. Electron. Agric. 2013, 91, 106-115. [CrossRef]

72. Abdulridha, J.; Ehsani, R.; Abd-Elrahma, A.; Ampatzidis, Y. A remote sensing technique for detecting laurel wilt disease in avocado in presence of other biotic and abiotic stresses. Comput. Electron. Agric. 2019, 156, 549-557. [CrossRef]

73. Hansen, P.M.; Schjoerring, J.K. Reflectance measurement of canopy biomass and nitrogen status in wheat crops using normalized difference vegetation indices and partial least squares regression. Remote Sens. Environ. 2003, 86, 542-553. [CrossRef]

74. Rodriguez-Caballero, E.; Knerr, T.; Weber, B. Importance of biocrusts in dryland monitoring using spectral indices. Remote Sens. Environ. 2015, 170, 32-39. [CrossRef]

75. Asaari, M.S.M.; Mishra, P.; Mertens, S.; Dhondt, S.; Inze, D.; Wuyts, N.; Scheunders, P. Close-range hyperspectral image analysis for the early detection of stress responses in individual plants in a high-throughput phenotyping platform. ISPRS J. Photogramm. Remote Sens. 2018, 138, 121-138. [CrossRef]

76. Sandmann, M.; Grosch, R.; Graefe, J. The use of features from fluorescence, thermography, and NDVI imaging to detect biotic stress in lettuce. Plant. Dis. 2018, 102, 1101-1107. [CrossRef]

(C) 2019 by the authors. Licensee MDPI, Basel, Switzerland. This article is an open access article distributed under the terms and conditions of the Creative Commons Attribution (CC BY) license (http://creativecommons.org/licenses/by/4.0/). 